\title{
El ara de las Parcae de Termes (Tiermes, Soria): nuevo documento y análisis sobre un probable sincretismo
}

\author{
Julio Mangas ManjarRÉs \\ Universidad Complutense de Madrid \\ juliomangas@yahoo.es \\ Santiago Martínez Caballero \\ Museo de Segovia \\ marcabsa@jcyl.es \\ Ángel Luis Hoces de la Guardia Bermejo \\ Doctor en Historia Antigua \\ hdg@hdgsg.net
}

Recibido: 11 de junio de 2013

Aceptado: 6 de julio de 2013

\section{RESUMEN}

En este artículo hemos estudiado el ara votiva consagrada a las Parcae, hallada en el sacellum situado en el santuario de Apollo en Termes (Hispania Citerior). El análisis de los espacios sagrados de la ciudad orienta a algún tipo de sincretismo con dioses prerromanos, quizás Lug y Matres.

Palabras clave: Nueva ara votiva. Parcae. Apolo. Termes. Sincretismo. Lug. Matres.

\section{Altar of the Parcae in Termes (Tiermes, Soria): new documentation and analysis about probable syncretism}

\begin{abstract}
In this article we have studied the votiv altar devoted to the Parcae, found in the Apollo sanctuary in Termes (Hispania Citerior). The analysis of the sacred spaces of the city seems to point to some kind of syncretism with pre-Roman deities, perhaps Lug and Matres.
\end{abstract}

Key words: New votiv altar. Parcae. Apollo. Termes. Syncretism. Lug. Matres.

Sumario: 1. El ara de las Parcas de Termes. 2. El templo de Apollo y las áreas templarias de la Termes prerromana y romana. 3. Las Parcae, Apollo y sincretismo en Termes y la Celtiberia. 4. ¿Apollo, Parcae y Matres en el santuario poliádico del arx de Termes? 


\section{El ara de las Parcas de Termes}

Durante las excavaciones llevadas a cabo en 2005 en el área pública central de la ciudad romana de Termes (Montejo de Tiermes, Soria), municipio julio-claudio de la Hispania Citerior, ${ }^{1}$ y heredero de la ciudad celtibérica arévaca de Tarmes/Termes, se recuperó un árula dedicada a las Parcae en un sacellum situado junto a la fachada norte del templo de Apollo, edificio de época julio-claudia construido inmediatamente al noreste del foro romano. ${ }^{2}$ El sacellum, construido en época de Claudio (42-54 d.C.), es una pequeña construcción de planta cuadrada, de 5,4 $\mathrm{m}$ de anchura y $9 \mathrm{~m}$ de longitud, con pequeño ábside en la cabecera y realizada con muros de mampostería. ${ }^{3}$

El árula, aparecida en dos fragmentos, fue recuperada en la unidad estratigráfica 4022, conformada por un depósito de relleno del s. V d.C., posterior a la destrucción del sacellum, en un momento por determinar entre el s. III y el IV d.C. También aparecieron en esta unidad otros tres fragmentos de aras anepígrafas. Actualmente, el ara se conserva, con los números de inventario 05/60/4022/33 y 05/60/4022/36, en el Museo Monográfico de Tiermes (Soria), anexo del Museo Numantino (Soria).

Se trata de una pequeña ara votiva de caliza de color rojizo, procedente de una cantera local. Se presenta fragmentada en dos partes. Medidas del soporte completo: $(13,8)$ x $8,6 \times 6,5 \mathrm{~cm}$; del soporte superior: $(8,5)$ x $8,6 \times(6) \mathrm{cm}$; del soporte inferior: $(5,3)$ x $6,5 \times 6,5 \mathrm{~cm}$. Altura de letras; $1,2-1 \mathrm{~cm}$. Espacios interlineares: $0,5 \mathrm{~cm}$. Interpunción: punto redondo.

Lo conservado presenta los elementos decorativos canónicos. El fragmento superior conserva en su cabecera el foculus y dos pulvini; por debajo: toro, listel y escocia (arriba y abajo). En él se conserva la parte superior del campo epigráfico con dos líneas. El fragmento inferior contiene tres líneas del campo epigráfico así como una pequeña parte del inicio de la primera moldura de la base. Falta el resto de la base. La unión entre ambos fragmentos es segura atendiendo a la fractura oblicua central de la línea 3 y a la parte superior del extremo izquierdo de la línea 4.

La superficie de unión de ambos fragmentos se encuentra muy erosionada y presenta pocos puntos de contacto directo entre ellas. El resto del árula se presenta igualmente muy desgastado, con ángulos romos producidos por la erosión. El campo epigráfico del fragmento superior presenta pérdidas en las líneas 2-3 por esquirlado, así como un gran desgaste de los surcos de las letras. El texto del fragmento inferior se conserva en mejor estado. Presenta el siguiente texto:

$$
\begin{aligned}
& \text { VALERI } \\
& {[---]} \\
& {[---]} \\
& \text { PARCIS } \\
& \mathrm{V} \cdot \mathrm{S} \cdot \mathrm{L} \cdot \mathrm{M}
\end{aligned}
$$

1 Sobre la ciudad romana de Termes, bibliografía: Argente - Díaz 1996; Martínez Caballero 2008. Sobre el municipium julio-claudio: Galsterer 1971; Wiegels 1985, 140; Gómez Santacruz 1994; Mangas Martínez Caballero 2004.

2 Sobre el Foro de Termes: Martínez Caballero 2010; ID. 2011; ID. e.p.

3 Martínez Caballero 2010, 241 y ss.; ID. 2011. 
Transcripción: Valeri(i) / [- - ] / [- - ] / Parcis / v(otum) · s(olverunt) · $l($ ibentes $) \cdot m$ (erito)

Traducción: "Los Valerios ... cumplieron con agrado el merecido voto a las Parcas".

El elevado grado de erosión de toda su superficie puede conducir a algún imaginativo a ver más restos de letras que los presentados, pero debemos admitir que varios rasgos dispersos en toda su superficie son un simple producto de la erosión que afecta de modo más intenso al espacio donde debieron estar las líneas 2-3. En estas líneas, se podría esperar tanto el cognomen de dos Valerii como, probablemente mejor, una fórmula como pro salute (abreviado o en letras más pequeñas) en la lín. 2 y un nombre personal en la lín. 3, es decir, el nombre de la persona a la que se desea que las Parcas alarguen el hilo de la vida.

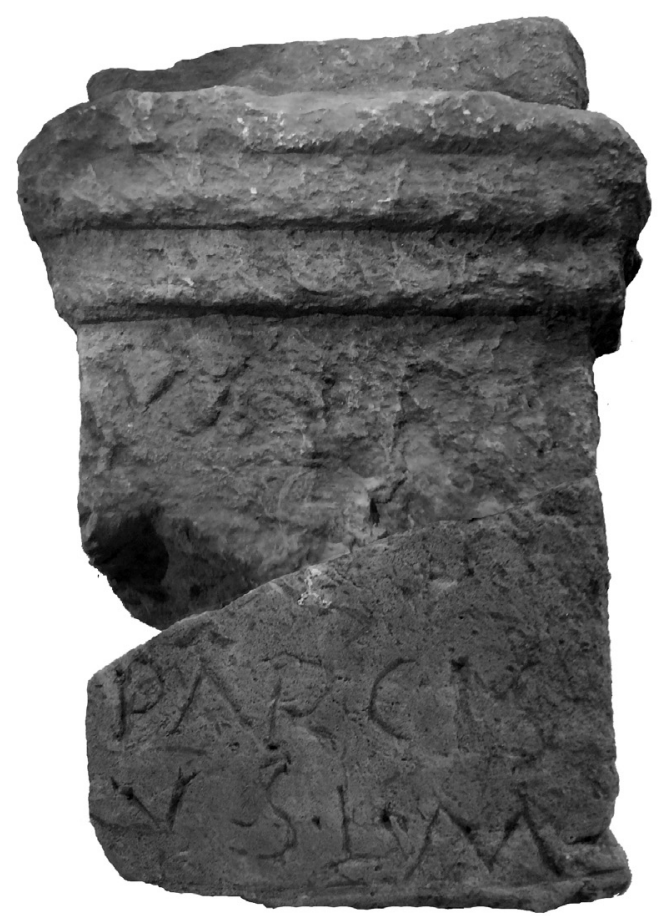

Fig. 1. Inscripción de las Parcae, recuperada en el sacellum del santuario de Apollo de Termes.

Datación: s. II d.C. avanzado, sin posibilidad de precisar más ni por paleografía ni atendiendo al contexto arqueológico, con materiales datados entre los siglos I-V d.C.

Los dedicantes del ara, los Valerii, portan un nomen bien conocido en Termes, en la dedicatoria a Marte por el militar L. Valerius Falernu[s C]otoninus, recuperada en el vecino pueblo de Noviales (Soria), y en los fratres Vitulus et Proculus Valerii 
Tarmestini, quienes dedican un ara a Lacipaea en Emerita Augusta. ${ }^{4}$ Se trata de un nomen bien documentado en Hispania y también en la Celtiberia (donde cabe reseñar la actuación del cónsul C. Valerius Flaccus a partir de 93 a.C. como origen del nomen para en algunos indígenas beneficiados con la concesión de la ciudadanía romana). ${ }^{5}$

Debe resaltarse que ésta es la primera ara votiva que conocemos en Hispania sobre las Parcae. Teníamos ya constancia de otras alusiones a las Parcae en inscripciones funerarias; así, en la hallada en un contexto no precisado de Sagunto, que se fecha en época augustea. Seguimos la lectura de Beltrán Lloris: ${ }^{6}$

M(arcus) Acilius L(ucii) f(ilius) / Fontanus / eripuit nobeis unde uicensumus annus / ingressum iu< $<>$ enem militiam cupide / Parcae falluntur Fontanum quae rapueru / nt / cum sit perpetuo fama futura viri

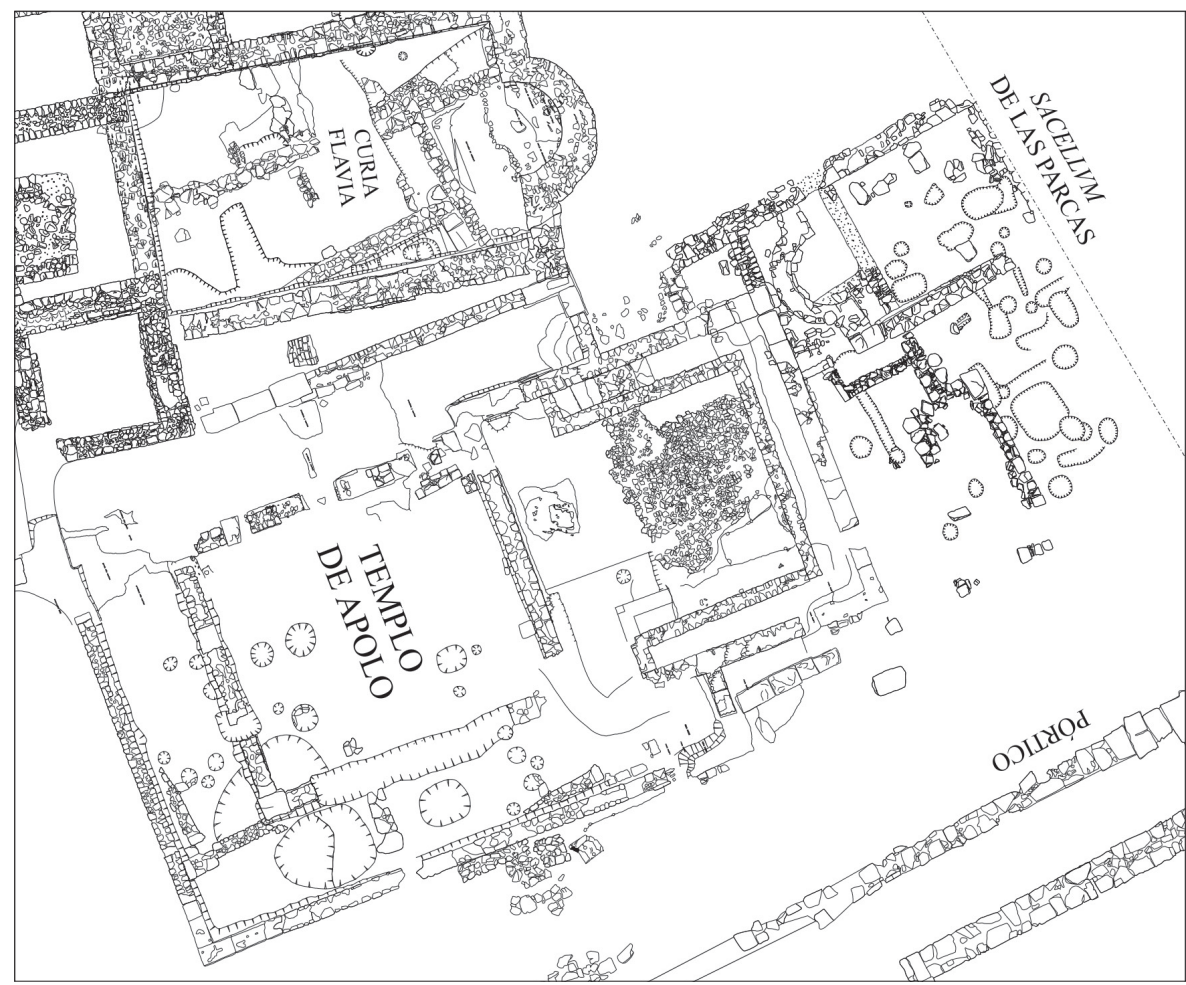

Fig. 2. Plano del santuario de Apollo y del sacellum de las Parcas. En la zona pública central de Termes.

4 Noviales: $A E$ 1998, 768; HEp 8, 1998, no 481; HEpOL 24212. Emerita Augusta: EE VIII, 23; HEpOL 22951.

5 OPEL IV 2002, 142-146, cita para Hispania 409+8 como nomen, y 17 como cognomen. AbasCal (1994, 232-244), indica que es el segundo gentilicio más frecuente en Hispania; cita 718 testimonios.

6 CIL II $3871=E L S T 83=$ CLE $978=$ CLENuovo, p. $117=C I L I^{2} / 14$, 347. Beltrán añade además la noticia sobre otra inscripción, referida también a las Parcae, procedente de Puzol, cuyo texto y lugar donde se encuentra sigue desconocido (Cf. CIL II 6064). Cf. Corell - Gómez Font 2002. 
Al margen de los patentes errores en la grafía de algunas palabras latinas (nobeis, uicensumus,...), el texto deja claro que estamos ante una inscripción funeraria referida a Marco Acilio Fontano, a quien, habiendo ingresado en la milicia, las Parcae cortaron el hilo de su vida. Estamos, pues, ante una visión plenamente romana sobre las Parcae, como las que se encuentran en Roma y en las ciudades de Italia. ${ }^{7}$ No debe olvidarse que Sagunto, con estatuto latino al menos desde comienzos del s. I a.C., era ya, a comienzos del Imperio, un municipio de ciudadanos romanos. ${ }^{8}$

Y, en la colonia Salaria (Úbeda la Vieja), se halló otra referencia a las Parcas en una inscripción funeraria, dedicada a una esclava, muerta en el parto: ${ }^{9} \ldots P a[r / c a$ fuer] as mihi si qu[a] / Inferi sapeni vi m[e] / abduceres...

\section{El templo de Apollo y las áreas templarias de la Termes prerromana y romana}

Desde los años 1980 se había considerado que el templo de Apolo de Termes constituía el templo de culto imperial del foro de la ciudad. La adscripción cultual del templo a Apolo la hemos considerado recientemente, tras el análisis de la evolución urbanística del área, la excavación llevada a cabo en el santuario y en el foro entre 2003 y 2006, así como tras la revisión de los hallazgos realizados en la zona desde las primeras excavaciones acometidas en el lugar. ${ }^{10}$

El foro de Termes se sitúa en el área extendida inmediatamente al suroeste de este templo, espacio foral que sufrió una continua evolución, fruto de sucesivas actuaciones edilicias. Comenzó a ser ordenado como tal ya desde el primer cuarto del s. I a.C., a partir de un santuario fundacional dotado de mundus y sacellum, relacionable con un culto ctónico (¿emplazado sobre un espacio cultual celtibérico?). Fue remodelado en época augustea, cuando se construyó un primer templo próstilo tetrástilo, donde planteamos identificar un capitolium, que presidiría el área abierta central. A su vez, sufrió una profunda remodelación en época flavia, mediante un gran proyecto escenográfico, siguiendo un modelo de cuadripórtico con templo de culto imperial integrado dentro de pórtico (lado septentrional del foro) y aedes Augusti / tribunal en la basilica (lado occidental). ${ }^{11}$ Actuaciones menores se llevaron a cabo en este complejo en el s. II d.C.

El templo de Apolo, como un santuario urbano, se emplazó en un espacio público sacro contiguo al foro, en la misma área pública central. Construido en época julioclaudia, constaba de una plaza central, porticada al menos en su lado oriental, en cuyo extremo meridional se levantaron el templo del dios titular del santuario y el sacellum de las Parcae. ${ }^{12}$

7 Grimal 1965, "Parcas".

8 Galsterer 1971, 28 y ss.

9 CILA 7, 362. Stylow ha sugerido que la lectura podría ser Pi $[a /$ axor...] por los trazos conservados en el final de la línea: cf. HEp 4, 1994, 495.

10 Martínez Caballero 2010.

11 Martínez Caballero 2010, 227-231.

12 Martínez Caballero 2010; ID. 2011. 
Durante las primeras excavaciones desarrolladas en el santuario, a principios del s. $\mathrm{XX}$, se recuperaron piezas que definen el carácter del santuario, como las siguientes: una estatua en bronce de Apollo, conservada en el Museo Arqueológico Nacional; ${ }^{13}$ un pequeño busto (de $17 \mathrm{~cm}$ de altura) que representa un sacerdote del dios, identificable por la corona trenzada de laurel, atributo de Apolo, con medallón, símbolo solar o estelar, y dos cintas que caen sobre los hombros, finalizando en una borla; ${ }^{14} \mathrm{y}$, en tercer lugar, el fragmento de una basa con inscripción, hoy perdida, con el texto Apo[---]. Atendiendo a las dos primeras piezas, el texto de tal inscripción corresponde mejor con el teónimo Apo[llo] que con un antropónimo (tipo Apo[llonius]). Tal dato nos lleva a identificar incluso el fragmento de la basa con un pedestal para una estatua de Apollo (¿acaso la estatua de bronce, igualmente simulacrum del templo?). ${ }^{15}$ Los indicios son suficientes como para deducir que Apollo fue el titular de este santuario urbano de primer orden, por sus dimensiones monumentales y por su ubicación junto al foro, principal espacio público de la Termes imperial.

Constituyen estos edificios los templos conocidos en la zona central de la ciudad romana: santuario fundacional (60-50 a.C.); templo augusteo (¿o capitolium?); santuario de Apolo con sacellum de las Parcas (época julio-claudia), aedes imperial y aedes Augusti / tribunal del foro flavio. ${ }^{16}$

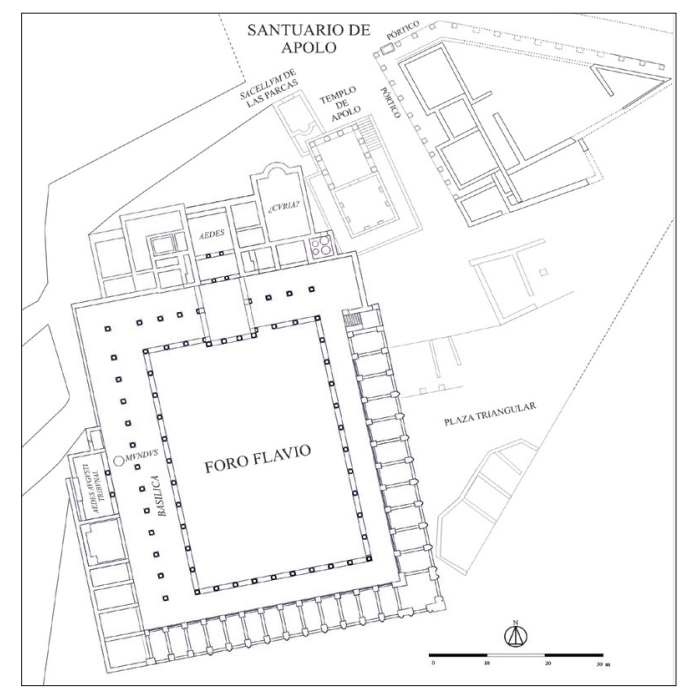

Fig. 3. Plano del área pública de Termes, con el foro y el santuario de Apollo.

13 Bibliografía en Martínez Caballero 2007.

14 Ruiz-Nicoli 2009, 110-111, $\mathrm{n}^{\circ} 22$.

15 Sobre el hallazgo, Calvo 1913, 383.

16 Recordamos el denominado "Templo de Baco", representado en los primeros planos del yacimiento de Tiermes. Ver: Figueroa y Torres 1910, 17 y plano; Sentenach 1911, 289; Calvo 1913, 383. Ante la escasa documentación y el desconocimiento de las estructuras que fueron vistas a principios del s. XX, sólo podemos apuntar que quizás se corresponda con un espacio público o con un área de representación de un edificio privado. 
En la parte más alta del cerro donde se asienta la ciudad, en el arx de Termes, existió también otro santuario urbano. La primera noticia sobre las estructuras de la acrópolis de Tiermes la aporta el Conde de Romanones a principios del s. XX. Habla de escasos restos de construcciones, que considera de planta basilical, quizás perteneciente "á alguna primitiva ermita ó capilla". ${ }^{17}$ Schulten, quien visitó también el lugar a comienzos del $\mathrm{s}$. XX, ofreció una primera interpretación más acertada, ${ }^{18}$ además de un plano del lugar. Por su valor, reproducimos algunas de sus consideraciones:

En el poyo que da remate á la punta Oeste de la ciudadela, pusimos de manifiesto una construcción rectangular dividida en varios compartimentos, que evidentemente lo fueron de un templo. Además de varios fragmentos romanos é ibéricos, en este templo hallé un trozo de inscripción romana, parte quizás de un ara votiva (...) El titular del templo romano es de presumir que fuese Mercurio, toda vez que la fiesta de Nuestra Señora de Tiermes cae el 15 de Mayo, que coincide con los idus de Mayo, día en que se celebra el aniversario del nacimiento del hijo de Maya...

El dibujo de los restos de la inscripción que aporta Schulten permite efectuar la siguiente transcripción:

$$
\text { - - - - - /SEF[- - - ]/SF [- - - ]/ME[-- - ]/ - - - - }
$$

Resulta imposible garantizar que se trate de un ara consagrada a Mercurio, como creyó Schulten. ${ }^{19}$

Taracena precisaba más al hablar de que "en la pequeña terraza de la cumbre, bajo ruinas posteriores, se adivina con dificultad la excavación rupestre de un edificio indígena que después modificaron los romanos, acaso un templo, mas sin otro dato que su emplazamiento para suponerlo". ${ }^{20}$

Argente, con su equipo, entre los años 1970-1990 aludía a las informaciones anteriores de Taracena y aceptaba que podía haber un templo arévaco, al que sucedió un templo de época romana. ${ }^{21}$

Almagro-Gorbea y Lorrio, tras realizar en 1999 unos trabajos de limpieza del área, han publicado recientemente un análisis del conjunto, que aporta una serie de nuevas conclusiones sobre la evolución del lugar. ${ }^{22}$ Para estos autores, el santuario parte de un primitivo templo gentilicio ubicado en una cabaña de la I Edad del Hierro, vista en parte durante esos trabajos. Ese templo-cabaña, relacionado con un culto de los antepasados, sería sucedido en una etapa muy avanzada, anterior a la conquista romana, por un templo poliádico celtibérico, dedicado a un culto heroico local, al Héros

17 Figueroa y Torres $1910,15$.

18 SChulten 1913, 573-574; 773.

19 SChULTEN 1913, 573, n. 2. ME [---] en cuarta línea se ha transcrito como Me [rcurio] (BaraTta 2003, 69, T12 Sp). SEF [---] en lín. 2 podría ser un antropónimo tipo Sefitius (CIL IX, 4549). SF en lín. 3 podría ser $S E$ (para Mercurius se conocen los epítetos Secate-CIL XIII 4550- y Seno[---] -CIL XIII 6334-).

20 TARACENA 1941, 107; ID. 1954, 239, figs. 126 y 128.

21 Argente et alii, 1988, 56; Argente - Díaz 1990, 60; Argente - Díaz 1996, 118.

22 Almagro-Gorbea - Lorrio 2012, 123 s. Comentarios precedentes: Almagro-Gorbea 1994; AlmagroGorbea - Berrocal 1997, 197; Almagro-Gorbea - Abascal 2008. 
Ktístes o Héroe Fundador de Termes, cuyo nombre sería Termes/Tarmes. Sobre estas estructuras se colocaría una atalaya en época islámica.

En el contexto del proyecto LIFE-Tiermes, S. Martínez Caballero y J. Santos Yanguas han vuelto a replantearse nuevas cuestiones sobre los restos de ese conjunto del arx, sumándose, en una pequeña reflexión, a la opinión de que se trataba de un lugar sacro en el que se erigieron sucesivos edificios de culto, de época prerromana y romana..$^{23}$

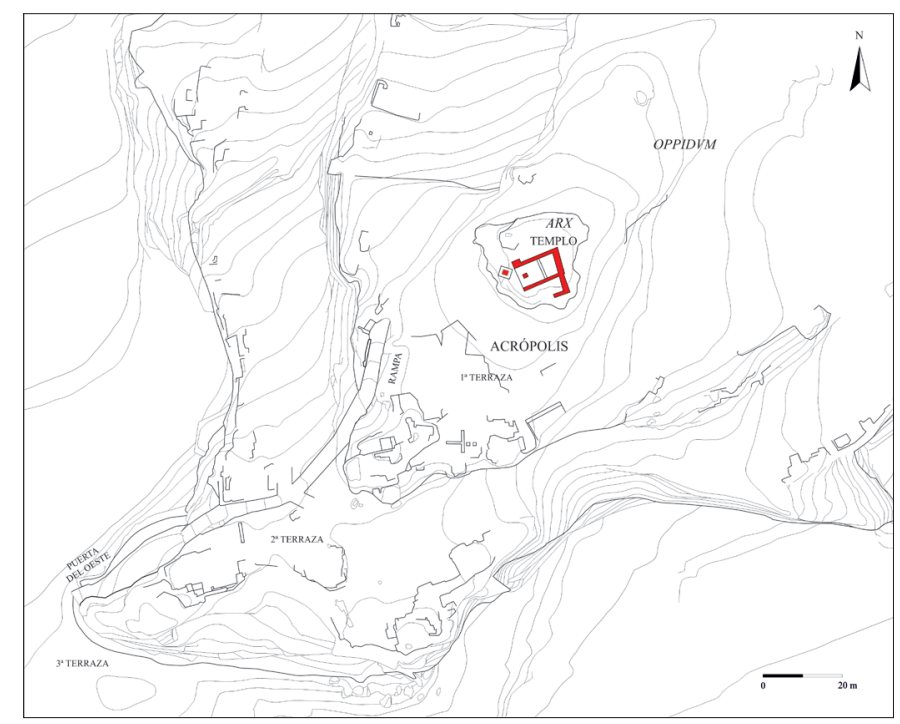

Fig. 4. Plano de la Acrópolis de Termes, con localización del santuario del Arx.

Como resultado de nuevos trabajos en los años 2000, hemos vuelto a retomar la interpretación del conjunto. ${ }^{24} \mathrm{Si}$ bien reconocemos la presencia del santuario gentilicio arcaico sobre la cabaña del Celtibérico Antiguo, como proponen Almagro-Gorbea y Lorrio, no compartimos el resto de la interpretación de estos últimos autores. Más allá de los escasísimos indicios arqueológicos reconocidos en el arx que puedan vincularse sensu stricto con un santuario heroico (la supuesta eschara no es indicador directo de culto heroico y el resto de componentes arquitectónicos son habituales en templos ctónicos y uranios), y la carencia de elementos epigráficos, funerarios (materiales o simbólicos, fundamentales para una buena interpretación) o escultóricos (imagenes maiorum, etc.), propios de herôa, estos autores tampoco tienen en cuenta en su análisis datos como los siguientes: la presencia de un santuario urbano de Apollo en una ciudad de origen céltico como Termes, especialmente venerado en el occidente romano (como veremos), y la superposición de un templo romano sobre el templo celtibérico, identificado en la estructura erróneamente interpretada como atalaya islámica.

23 Martínez Caballero - Santos 2005, 689.

24 Martínez Caballero - Mangas e.p. 
En el arx de Termes se documenta, por tanto, la superposición de tres templos. El llamado santuario gentilicio en cabaña, asociado a un primer pozo ritual, según la evaluación e interpretación propuesta Almagro-Gorbea y Lorrio, se dataría en el Celtibérico Antiguo (hacia los siglos VI/V a.C.). Este templo sería amortizado por el santuario celtibérico posiblemente en el s. II a.C. Estaba asociado a un gran pozo ritual (mundus, bothrós). Creemos que este templo estuvo dedicado a una deidad plurifuncional, no heroica, según veremos más adelante. El templo poliádico celtibérico fue amortizado con la construcción del templo romano, que se elevó sobre el anterior, acogiendo el culto precedente pero sometido a un proceso de transformación sincrética. Atendiendo al momento del sometimiento de Termes a Roma (98/97 a.C.) y al modelo arquitectónico (escalinata central, abierta hacia el Sur, sobre un podium con corredores laterales), este templo pudo haberse construido en el s. I a.C. - inicios del s. I d.C., en el contexto de la transformación urbana que desvelan los primeros análisis sobre la monumentalización del foro, entre época tardo-republicana y augustea.

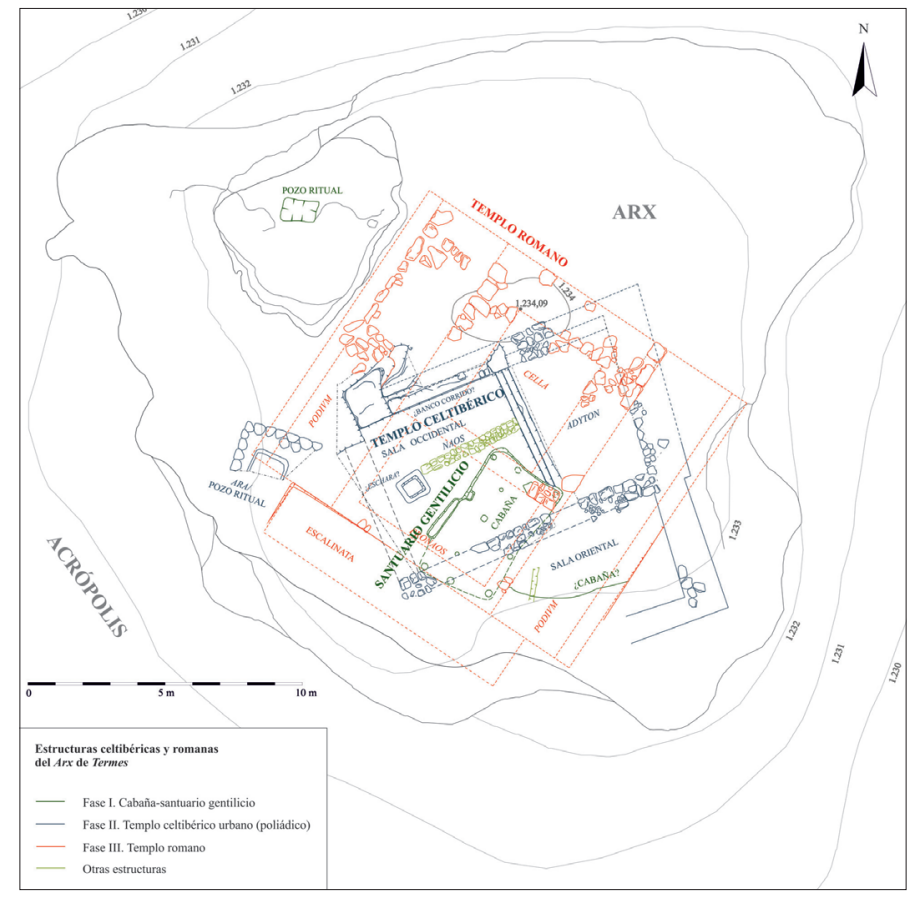

Fig. 5. Plano de los templos superpuestos del Arx de Termes.

Cabe reseñar que por debajo del mundus del templo poliádico se situaban dos pequeñas cuevas, con abertura hacia la plataforma donde se eleva el templo. Estos espacios debieron acoger ya rituales del templo celtibérico, de carácter más intimista (oraculares o iniciáticos, incluso con componentes catárticos y cruentos, etc.), propios de una esfera conceptual ctónica y funeraria, que acompaña habitualmente la sa- 
cralización de grutas, cavidades y cuevas. Situándose en esa posición bajo el mundus, la concepción ritual de estos antros estaría cercana al templum sub terra centroitálico y al mundus Cereris o sacrum Cereris, antesala de descenso al submundo de Ceres / Tellus. ${ }^{25}$ No sería imposible que sirvieran de lugares desde donde una adivina emitía presagios, como se dice de la fatidica puella de Clunia. ${ }^{26}$ Ahora sabemos que el pozo ritual de Clunia comunicaba con las cuevas situadas debajo de la ciudad, donde se han hallado monedas e inscripciones con referencias a los magistrados de la ciudad. ${ }^{27}$

\section{Las Parcae, Apollo y sincretismo en Termes y la Celtiberia}

Se considera a las Parcae deidades del destino y la Fortuna, desde su identificación con las Moiras griegas. Su culto partiría de númenes asociados al nacimiento. De ahí el nombre de Nona y Decima con referencia a los meses en los que se producen los partos. La tercera alternaría entre Morta y Parca (Partula en Tertuliano). Si bien Gelio habla de la Parca itálica ancestral con el nombre de Morta $^{28}$ (los etruscos la habrían denominado Muira, según aparece en un espejo de Chiusi con el tema de la muerte de los hijos de Níobe). En cualquier caso, las Parcas presentan fuertes contenidos ctónicos y funerarios. Son las divinidades que deciden el fatum, pues determinan la duración de la vida y provocan el acontecimiento de la muerte. ${ }^{29}$ Por ello aparecen en carmina epigraphica, donde se manifiesta la asunción plena del ineludible hecho de la muerte. ${ }^{30}$

El hallazgo del ara de las Parcas en el sacellum del santuario de Apollo en Termes declara la especial vinculación entre ambas divinidades en la ciudad. No es un hecho frecuente. En Nemausus (Nîmes, Gallia Narb.), Salonae (Solin, Ilyricum) y Aquincum (Budapest, Pannonia Inf.) se reconoce también, aunque a través de diferentes epígrafes, el culto a ambas divinidades. ${ }^{31} \mathrm{La}$ asociación entre estas deidades en una misma inscripción es conocida en un carmen sepulchrale de Mogontiacum (Mainz, Germania Sup.), ${ }^{32}$ donde su concurrencia parte de un uso literario, que expresa, a través del aparente antagonismo de las divinidades, la pertenencia a un similar sistema de creencias, construido desde la suma de extremos.

25 Fest. 126 L.

26 Suet., Galba, IX, 2: nam et mandata Neronis de nece sua ad procuratores clam missa deprehenderat et confirmabatur cum secundissimis auspiciis et ominibus, tum virginis honestae vaticinatione, tanto magis, quod eadem illa carmina sacerdos Iovis Cluniae ex penetrali somnio monitus eruerat, ante ducentos annos similiter a fatidica puella pronuntiata. Quorum carminum sententia erat, oriturum quandoque ex Hispania principem dominumque rerum.

27 Ya se ha escrito mucho sobre las sacerdotisas celtas y la adivinación. Una buena síntesis en DE VRIES $1961,217-219$.

28 Gell., 3.16.10-11.

29 Sobre las Parcas: Brelich 1937, 28-29; Van der Horst 1942; Weinstock 1952; Tels de Jong 1959; De Angeli 1992; Perfigli 2004, 82-83 y 95.

30 SOPEÑa 2009, 263.

31 Nemausus: AE 1992, 1217; AE 2003, 1137 (Apollo), CIL XII 5890 (Parcae). Salonae: AE 1913, 42; 1912, 39; CIL III 8659 y 14745 (Apollo); CIL III 6384 y 9106 (Parcae); AE 1912, 42. Aquincum: AE $1952,1$.

32 CIL XIII 6808. También aparecen en un epígrafe mitraico tracio de Nikopol (CIL III 754). 
Existe una estrecha relación entre las Parcae y Apollo. Apollo es garante de la armonía y del funcionamiento del cosmos, al constituir el inicio y el final de la circulación armónica del mundo, y sobre su carro (Apollo Helios) el dios surca el cielo al amanecer, ascendiendo hasta el mediodía, para caer por la tarde y penetrar finalmente en el mundo subterráneo, trayecto con el que comunica el mundo de los vivos con el de los muertos, adoptando por ello un carácter psycopompo. Este viaje sirve de nexo entre los ámbitos celeste, terrenal e infernal, y reconduce a las prerrogativas onfálicas y ctónicas del Apollo Deplhinios, de donde emana la esfera oracular y profética del dios. La naturaleza ctónica y profética de Apollo complementa el sistema de creencias en el que están inmersas las Parcae.

Considerando esta naturaleza, en los contextos célticos europeos, al que pertenece Termes, se considera a las Parcae como la interpretatio de las Matres, también deidades de carácter ctónico y funerario, aunque muy conectadas con el culto a las aguas. Estas diosas, generalmente tres, tuvieron una fuerte implantación en las Galias, en Germania y en Britania, pero también en ámbitos célticos de Hispania. Dentro del ámbito hispano, donde es bien conocido su culto, ${ }^{33}$ la mayor parte de los testimonios conocidos de las Matres se concentran en la Celtiberia: en el territorio arévaco, pelendón y berón, y en especial en las ciudades arévacas de Clunia (Coruña del Conde, Burgos) ${ }^{34}$ y Confloenta/Confluentia (Duratón, Segovia). ${ }^{35}$ Otros documentos aparecen en Ágreda y Yanguas (Soria), así como en Salas de los Infantes (Burgos) y Canales de la Sierra (La Rioja). También aparecen en Laguardia y Badarán (La Rioja). En otras zonas de la Hispania céltica, contamos con el epígrafe de Bembibre (León); en el área vascona, con un pedestal con la dedicatoria a las diosas de Los Bañales (Uncastillo, Zaragoza). ${ }^{36}$

Con frecuencia, el teónimo de las Matres va acompañado de una advocación o referencia al lugar donde son veneradas (Gallaicae, Britannae, Nemausicae, Obelenses, Glanicae...) y son representadas como tres imágenes femeninas, a menudo situadas en la parte superior de las aras votivas; los testimonios del ámbito de Köln (Colonia) son elocuentes. A veces figuran como Matrae o Matronae y también como las Suleviae germanas y las Campestres galas. ${ }^{37}$

También se ha demostrado una estrecha interrelación entre los testimonios del dios céltico Lug / Lugus y las Matres, que se explicaría por el hecho de que la triplicidad de estas divinidades revelaría también un vínculo funcional entre las mismas. Para Lambrechts, las Matres serían incluso una transposición ternaria, en una dimensión solar, de Lug, deidad que también se manifiesta de forma plural y que, como veremos,

33 Gómez-Pantoja 1999; Solana - Hernández 2000; Olivares 2002, 254-255. En general, sobre las Matres en la Keltiké: Lambrechts 1942, 170; Vendryes 1948; TheVÉnot 1968; Green 1986, 78-79; RÜGER 1987.

34 CIL II 6338 L; CIL II 2776; ERClunia nº 13, 16, 17 y 28. Ver Gómez-PANToja 1999.

35 ERSg, pp. 84-87, $\mathrm{n}^{\circ} 17-18$.

36 Ágreda: ERPS 17-18, n 1; Yanguas: ERPS 51-52, n 35; Salas de los Infantes: AвÁsolo 1974, 149, $\mathrm{n}^{\circ}$ 206; Canales de la Sierra: HEp 1, 1989, 502; Laguardia: Albertos 1970, 158-159; Badarán: Castillo 1999, 137-140; Bembibre: Gómez-Pantoja 1999, 422, nº 1. Los Bañales: Jordán Lorenzo 2012, 86.

37 De VRIES 1961, 120-122. 
es asimilado en época romana también a Apollo, por la dimensión solar de ambas deidades.

El hallazgo del ara en el sacellum del santuario de Apollo es un dato muy notable, pues también llama la atención la conexión que se detecta por la epigrafía entre las Matres y Apollo en las áreas céltica, germánica, dácica e ilírica, donde conocemos varias dedicaciones a estas deidades..$^{38}$ También conocemos en Germania, Rhaetia y Pannonia lugares donde se testimonian los cultos de Apollo y las Suleviae. ${ }^{39}$ En Bonna (Bonn) se suma el culto de las Suleviae a los de Apollo y las Matres. El culto de las Campestres y Apollo lo conocemos también en Germania, Noricum, Pannonia y Dacia. ${ }^{40}$ En Salonae, a los mencionados cultos de Apollo y las Parcae, se suma el de las Matres ${ }^{41}$ La conexión entre las Matres y otros cultos solares se muestra en epígrafes como los de Corinium Dobunorum (Cirencester, Britannia), Agonès (Gallia Narb.), con dedicatoria a Mercurius y las Matres, y Mogontiacum, dedicado a las Matres Mogontionum. ${ }^{42}$ Significativo es el caso de Glanum (Sainte-Rémy-de-Provence, Gallia Narb.), donde al igual que en Termes, el templo de Apollo/Valetudo (deidad identificada con Apollo Belenos), y el santuario de las Matres Glanicae y Glan, dios tutelar epónimo, se situaban también en posiciones muy cercanas. ${ }^{43}$ A estos documentos sumamos el de Hispania: el hallazgo de sendos pedestales dedicados ex testamento a las Matres y quizás Apollo, en la denominada exedra del foro de Los Bañales (Uncastillo, Zaragoza), junto a otros dos pedestales con dedicaciones a Júpiter y quizás las Nymphae. ${ }^{44}$

La documentación del culto a las Parcae en el importante santuario de Apollo de la ciudad de Termes es un dato muy significativo, si consideramos la amplia difusión que tuvo el culto de Apollo en época romana en las comunidades de la Keltiké, como vamos a comprobar. A su vez, no debe olvidarse la especial relación entre las Parcae y las Matres prerromanas en los mismos ámbitos.

38 Massilia (Marsella): Str. 4.1 .4 (Apollo); AE 1977, 530; (Matres). Mogontiacum (Mainz) CIL XIII 6661, 6662 y 663 (Apollo), CIL XIII 6729 (Matres). Colonia Ara Agrippinensium (Köln, Colonia): AE 1906, 56, AE 1953, 269 (Apollo), AE 1984, 655 y 669, AE 1990, 733, AE 1998, 963 (Matres). Bonna (Bonn): AE 1945, 9 (Apollo), $A E$ 1930, 36, AE 1931, 15, AE 1945, 10 (Matres). Nida (Frankfurt-Hedderheim): AE 1977, 591 (Apollo), CIL XIII 7357 (Matres). Ulpia Traiana (Xanten): CIL XIII, 1328 (Matres). Apulum (Alba Iulia): AE 1956, 204, AE 1972, 456, AE 1980, 735, CIL III 983, 989, 990, 991, 1133, 1138, 14469 y 14470, IDR 3, 5, 669 (Apollo), AE 1980, 738 (Matres).

39 Köln (Colonia): para Apollo ver supra, n. 38. Aquincum (Budapest): AE 1982, 806, CIL XIII 3631 (Apollo), AE 19437, 212 (Suleviae). AE 1907, 107 (Suleviae). Xanten: para Apollo ver supra, n. 39; CIL XIII 1328 (Suleviae). Solva: CIL III 3649 (Apollo, AE 20051170 (Suleviae). Vicus Scuttariensium (Nassenfels): CIL III 5900 (Suleviae). Apulum: para Apollo ver supra; CIL III 1156 (Suleviae).

40 Bonna (Bonn): sobre Apollo, ver supra, n. 38; AE 1931, 25 (Campestres). Heilbronn: CIL XIII 6469 (Apollo), CIL XIII 6470 (Campestres). Virunum: CIL III 4774 (Bellino Augusto); AE 2004, 1075 (Campestres). Brigetio (Szöny): AE 1894 (Apollo), CIL III 14355 (Campestres). Obernburg: ILS 2602 (Apollo), AE 2003 (Campestres). Sarmizegetusa: AE 1911, 32, AE 1971, 376, AE 1977 673, AE 1983, 828, 835, 841, AE 2001, 1716 (Apollo), CIL III 7904 (Campestres).

41 AE 1912, 42.

42 Corinum Dobinorum: AE 1975, 532. Agonès: AE 1986, 471. Mogontiacum: CIL XIII 6729.

43 Bedon 2001, 290-291.

44 JoRdÁn Lorenzo 2012. Sobre el foro de Los Bañales: ANDreu 2011. 
Como ya se ha resaltado, ${ }^{45}$ la incorporación inicial del culto de Apolo en Roma tuvo lugar a fines del s. VI a.C. (como propone F. Coarelli), o el 431 a.C., tras la llegada de la comisión enviada a Delfos. De Apollo se esperaba que pudiera salvar a la ciudad de la terrible peste que padecía; fue, pues, incorporado como dios salutífero ante la incapacidad de la diosa Febris de librar a la ciudad de la peste. Desde entonces, Apollo pasó a ser la divinidad más importante de la salud, mientras Febris quedó marginada, aunque, todavía en época del emperador Claudio, había quienes acudían a su templo para adquirir hierbas u otros productos medicinales. ${ }^{46}$ Este culto salutífero de Apolo derivó directamente de la esfera funcional de los numerosos cultos sanadores del Apollo griego (Iatros, Paiàn y Oulios, principalmente), algunos dotados también de componentes oraculares y epifánicos.

Esa advocación prioritaria salutífera de Apollo se difundió en Italia y luego en medios provinciales, facilitando su sincretismo con divinidades locales de la salud, ante todo con las divinidades de aguas salutíferas. Entre varios testimonios epigráficos de Hispania referidos a Apollo, baste recordar aquellos en los que resulta más evidente la relación de Apollo con las aguas salutíferas: ${ }^{47}$ Caldas de Montbuy con tres dedicatorias; Caldas de Malavella (¿Aquis Voconis?, Gerona); Aurgi (Jaén), junto a un centro de aguas salutíferas, situadas hoy en el ámbito de una ermita; Valencia de Alcántara (Cáceres), junto a la Fuente Blanca y junto a otra ara consagrada a Salus; Arucci, en el yacimiento de Fuente Seca; Valle de Abdalajís (territorio de Nescania, Málaga), donde, además de las aguas salutíferas, usadas hasta fechas recientes, se halló el ara dedicada a Apollo y a su hijo Aesculapius, dios médico. ${ }^{48}$

La progresiva helenización de la sociedad romana fue creando las condiciones para que el Apollo Delphinios terminara por generalizarse con todas sus advocaciones griegas en el mundo romano occidental. El mayor impulso vino del primer emperador, de Augusto. Éste, agradeciendo a Apollo el feliz resultado de la batalla de Accio, no dudó en erigir un templo de Apollo en el Palatino; hasta entonces, sólo había un templo de Apollo en Roma, situado fuera del pomoerium. El 17 a.C. Augusto dio un nuevo apoyo a Apollo con ocasión de los Juegos Seculares. ${ }^{49}$ Desde entonces, el Apollo romano era ya abiertamente un Apollo con todas las advocaciones del Apolo Délfico: dios de la salud, de la adivinación, divinidad solar, dios de la vegetación, dios de la música e incluso dios de la guerra (su arco y sus flechas). ${ }^{50}$

Esos cambios, iniciados desde fines de la República y consolidados bajo Augusto, facilitaron el sincretismo de Apolo con muchos importantes dioses del panteón céltico y de otras poblaciones prerromanas mediterráneas y continentales.

45 Bayet 1969, 124; Dumézil 1966, 429-430; CoArelli 1997, 380 ss. A pesar de ser Asclepio / Esculapio, hijo de Apolo y también dios curador, su culto no entró en Roma hasta el 293 a.C.: Cf. DuMÉZIL 1966, 430-431.

46 El santuario de Febris en Roma estaba situado en el Janículo: Cf. BAYET 1969, 208.

47 Cf. Mangas 1992, 176; 184-185; 186.

48 Aquae Calidae (Caldas de Montbuy): CIL II 4487, 4488 y 4489; Caldas de Malavella (Aquae Calidae/ Aquae Voconiae): CIL II 6181. Aurgi: CIL II $2 / 5,25=$ CIL II 3358 (p. 951) = CILA 6, 16. Valencia de Alcántara: AE 1968, 211; CPILC 593. Arucci: CIL II $964=$ ERBC $161=$ ILS 5402. Valle de Abdalajís: CIL II 2004.

49 BAYET 1969, 177-179. La especial relación de los Iulii con el culto a Apollo se remontaba ya a la introducción del mismo en Roma (ver supra, n. 45).

50 Una buena síntesis en Grimal 1965, “Apolo". 
En el área de sustrato céltico, la asunción plena de todas las advocaciones griegas de Apollo, ante todo desde Augusto, condujo a que se sincretizara con varias divinidades célticas ${ }^{51}$ sobre todo con Lug / Lugus, ya que ambas divinidades participan de similar esfera conceptual, por funcionalidad, atributos y contenido de sus relatos mitológicos, así como por su carácter solar. ${ }^{52}$ Sergent plantea incluso que ambos dioses serían identificables..$^{53} \mathrm{Lug}$, el luminoso, joven y bello, al igual que Apollo, encarnaba el poder solar, celeste y ctónico, así como un carácter oracular. A veces, era considerado como "rey de los dioses", aunque no detentara el poder supremo, al ser hijo de Eithne, personificación de la soberanía, lo mismo que Apollo, hijo de Zeus / Iupiter. ${ }^{54}$ Cuando De Vries compara las semejanzas entre el Lug / Lugus céltico y su equivalente germano Wodan encuentra las siguientes: Lug es dios principal de los galos como Wodan lo es de los germanos, ambos dirigen el ejército, luchan con la jabalina, emplean la magia en la batalla, son maestros de la poesía, se relacionan con el cuervo y, mientras Lug cierra un ojo en sus actuaciones mágicas, Wodan es tuerto. ${ }^{55}$ Ante tal multiplicidad de funciones, resultó fácil que Lug se sincretizara con Apollo. Tales sincretismos se facilitaron en el ámbito céltico desde el momento en que, en Roma, se ampliaron las advocaciones de Apollo.

La interpretatio de Lug se concretó con frecuencia en un sincretismo con el Mercurius romano, divinidad protectora de los viajeros y los comerciantes,${ }^{56}$ de la que existen centenares de inscripciones en la Gallia y Germania, así como numerosas imágenes, donde la manifestación plural, en especial la iconografía tricéfala, encuentra su proyección en el Hermes también tricéfalo. ${ }^{57}$ Pero también es habitual su identificación con Apollo. La documentación en estas áreas de dedicatorias a Apollo y Mercurius puede señalar también la presencia de dos divinidades de origen sincrético diferente, aunque también se ha detectado en ocasiones que aquellas pueden surgir de la fragmentación conceptual de una única divinidad plurifuncional. Podemos estar ante casos de refuerzos de las advocaciones, desde una bilateralidad funcional emanada de un culto plurifuncional prerromano. ${ }^{58}$

La naturaleza compartida de Apollo y Lugus también aparece en Belenos, dios suprarregional solar y acuático documentado especialmente en el arco extendido entre la Narbonense, Gallia Cisalpina (principalmente en Aquileia, de donde era dios poliádico) y el Noricum $^{59}$ (donde era dios poliádico en Virunum y, antes, en Magdalensberg, capital nórica prerromana). Belenos se considera como una verdadera manifestación

51 De VRIES 1961, 71-78.

52 En general, sobre Lugus: Loth 1914; Even 1956; De VRIEs 1963, 59 ss.; MaC CANa 1983, 24-25; Hatt 1985; Green 1992; Olmsted 1994; Sergent 1995.

53 Sergent 1995.

54 Sergent 1995, 106-107.

55 DE VRIEs 1961, 54.

56 Sobre el culto a Mercurius en Hispania, BARATta 2001.

57 DE VRIES 1961, 40-41.

58 Así parece documentarse, en especial, en el relieve de Reims, donde aparecen Apollo (acompañado de un toro, símbolo de potencia y solar) y Mercurius entre una divinidad cornuda sedente, Cernunnus, considerada como una manifestación de una faceta de la divinidad solar. Cf. DeonnA 1941, 148 y ss.

59 Tert., Apoll. XXIV. 
alpina, véneta y nórica del propio Lug, y se sincretizó habitualmente con Apollo. ${ }^{60} \mathrm{Cabe}$ reseñar que Belenos se relaciona con el dios solsticial que transporta a los muertos en su barca a las divinas aguas de Danu, para que renazcan en el otro mundo, carácter psycopompo compartido con el Apollo oracular y solar. Tal dato conecta con la especial relación entre la dimensión ctónica de las deidades solares célticas principales y las Matres.

El aspecto sanador de Apollo también se proyectó en el sincretismo con divinidades de las aguas, tanto en el ámbito céltico como en otros, sin que necesariamente se borrara su dimensión solar. Entre estas divinidades sanadoras y salutíferas con componente solar que se asimilaron a Apollo encontramos al mismo Belenos, así como Grannus, Bormo y Maponos.

Al igual que en la Gallia, Lug era una deidad bien conocida en Hispania, en especial en el área galaica, y de forma más puntual en la Celtiberia ${ }^{61}$ En el Noroeste se documentan los Lugoves Arousae y Lugoves Gudarovi(i), testimoniados en sendas aras halladas en la excavación de un templo de Lucus Augusti (Lugo), así como los Lucouves Arquieni en Sinoga (Rábade, Lugo), los Luguves Arquieni en San Martín de Liñarán (Sober, Lugo) y los Lucuves Arquieni(...) en San Vicente de Castillones (Monforte, Lugo). ${ }^{62}$ En Peña Amaya (Burgos) se testimonian los Dii Magni Lugoves, en Atapuerca (Burgos) unas Deae Lugunae y de la Beturia céltica procede el epígrafe tartésico [J.1.1] de Fonte Velha (Bensafrim, Lagos), en el Algarve, donde se invoca a los Lugoves del pueblo de los Neri (lokooboo niiraboo), o bien se recoge un etnónimo (Neri). ${ }^{63}$ En la Celtiberia, Lug se testimonia en el santuario de Peñalba de Villastar (Teruel) ${ }^{64}$ aunque ha sido un tema debatido ${ }^{65}$ y en Vxama (Osma, Soria), en una dedicatoria a los Lugoves. ${ }^{66}$ De Fuensabiñán (Guadalajara), junto a Segontia (Sigüenza), procede una inscripción donde no es clara la lectura del texto, con teónimo Lug[---], o antropónimo Luc[ius]. ${ }^{67}$ También Lug aparece en Hispania en etnónimos (Lougei, Luggoni) ${ }^{68}$ y topónimos, en especial en el Noroeste (civitas Lougeiorum, civitas M. Lugonium-civitas Luggonum), ${ }^{69}$ así como en antropónimos y grupos suprafamiliares, como Lougeidocum (Segobriga, Saelices, Cuenca), Lougesterico(n)

60 De Vries 1963, 83-84; Mac Cana 1968, 24 y ss.; Hatt 1985, 210 y ss.; Green 1986; Olmsted 1994, 386-387; WoJCIECHOWSKI 1996; EUSKIRCHEN 1997; ZACCARIA 2010.

61 Sobre Lug en Hispania, atender la revisión de MARCO 2006. Bibliografía y análisis precedentes: Blázquez 1962, 174-136; Tovar 1982; Marco 1986; Salinas 1986; Sopeña 1987; Marco 1993 y 1994 ; Sagredo - Hernández 1996; Olivares 2002; Beltrán et alii 2005; García Quintela - Santos 2008,98 y ss.; Alfayé 2009; Marco 2009; Alberro 2010.

62 Marco 2006. Lucus Augusti: González Fernández - Rodríguez Colmenero 2002. Sinoga: Le Roux Tranoy 1973, 230-231. San Martín de Liñarán: Arias - Le Roux - Tranoy 1979, 87-88, nº 67. San Vicente de Castillones: Ares 1972, 85-187.

63 Peña Amaya: CIL II 6338v. Atapuerca: Solana et alii 1995, 191-203. Fonte Velha: Correa 1981.

64 Ver supra. n. 61.

65 JoRdÁn Cólera 2005a, no considera teónimo el término luguei de la inscripción del santuario, y la relaciona con el verbo "jurar", que aparecería también en la raíz de $L u g$, desde *leug(h)-.

66 CIL II 2818; ERPS, 38-40, $\mathrm{n}^{\circ} 22$.

67 AE 1987, 649; Gamo 2012, 241-244, nº 122.

68 Lougei: IRL 55. Luggoni: Ptol., 2.6.32; HAE 1037 y 1039.

69 Civitas Lougeiorum: IRL 55. Civitas M. Lugonium, civitas Luggonum: HAE 1037 y 1039. 
en Clunia y Lougesteric(um?) (Pozalmuro, Soria). ${ }^{70}$ Por su parte, Belenus no parece estar testimoniado en Hispania. ${ }^{71}$

La multiplicidad de funciones atribuidas a Lug / Lugus ayuda a entender los plurales como el de la inscripción antes mencionada de Vxama, cuyo texto completo dice: Lugovibus sacrum L(ucius) L(icinius) Urcico $(m)$ collegio sutorum d(edit) d(edicavit). Es claro que se trata de una asociación de zapateros y toda asociación decidía qué divinidad elegía como protectora. La dedicatoria incide en la consideración de Lug como maestro de las artes. Y aunque a veces la divinidad elegida tenía una advocación única o preferente (Mars para los campesinos o para los militares, Mercurius o Hercules para los comerciantes y viajeros, Diana para las asociaciones de mujeres o bien para los cazadores...), una divinidad multifuncional (Iupiter, Apollo...) podía igualmente ser elegida como protectora de una asociación. Tal plural, Lugoves, reflejaría la trifuncionalidad del dios, sin duda una divinidad muy conocida entre la población de Vxama con larga tradición céltica.

De otro lado, las menciones de Lug en Hispania se realizan sistemáticamente en plural y, según indican los textos, las dedicatorias mayoritariamente las efectúan mujeres. Considerando además el teónimo femenino de Atapuerca, se ha pensado en la hipótesis de relacionar estos plurales con una naturaleza femenina de la divinidad, en conexión con el hermafroditismo de ciertas fuentes iconográficas romano-célticas. ${ }^{72}$

Con todos estos datos, es plausible plantear la hipótesis de que el Apollo de Termes, ciudad de origen céltico, pudo haber derivado de la interpretatio romana de una divinidad indígena plurifuncional, cuyo carácter celeste, terrenal y ctónico se habría proyectado en el contenido apolíneo solar y oracular grecolatino. Con el culto prelatino se habría conectado estrechamente un hipotético culto de las Matres, deidades luego identificadas con las Parcae greco-romanas. La formulación solar y plurifuncional del Apollo grecolatino y céltico, y la especial presencia de Lug en la Celtiberia, nos orientan a proponer que el Apollo de Termes puede proceder de la interpretatio de Lug / Lugus, o bien de una deidad de carácter regional o local de la misma naturaleza y similares funciones. Por tanto, la estatua de Apollo de Termes representaría a la divinidad sincrética, ya con rasgos greco-latinos, según se repite en numerosas ocasiones para este tipo de representaciones.

Este sincretismo es acorde con el contexto histórico de Termes en los primeros momentos del Imperio. La anécdota contada por Tácito sobre un termestino que asesinó a Lucio Calpurnio Pisón, ${ }^{73}$ legado jurídico de la Tarraconense en el año 25 d.C., y que,

70 VAllejo 2005.

71 Se plantea que un ara dedicada a Obelleginus, en Olmos de Ojeda (Palencia; AbÁsolo - Alcalde 1996), podría tener algún tipo de conexión con la divinidad. También se ha relacionado con Belenos el teónimo Baelisto y Baelibio, del monte sagrado Bilibio, así como algunos topónimos en Asturias (GARCíA ARIAS 1976). Se ha asociado el topónimo Veleia (Iruña, Álava) con la misma raíz (la ciudad es citada como Beleia en It. Ant. 458 y Bellegia en Rav. 318,7), localidad de donde proviene una estela en la que quizás se representaría a Belenos (SAN Vicente 2008, 79-80). Un Balanus, rey galo, (Liv. XLIV 14.1) es conocido en Tañine (San Pedro Manrique, Soria, $A E$ 2001, 1222)

72 Marco 2006, 211 y ss. Como ya habían propuesto Olivares 2002, 113 y Jordín Cólera 2005 a. También aparecen en plural las dedicatorias de Nemausus (Nîmes, CIL XII 3080) y Aventicum (Avenches, CIL XIII 5078).

73 Tac., Ann., 4, 45. 
cuando fue hecho prisionero y sometido a tortura, respondía en su lengua vernácula, patrius sermo, no debe entenderse, en nuestra opinión, como una demostración de que la mayoría de la población de Termes no habría aún asimilado nada de la cultura romana a comienzos del Imperio. Habían transcurrido cien años desde el sometimiento de Termes a Roma y esta ciudad comenzó pronto a ser un foco importante de inmigración de población itálica.

La gran riqueza de la comunidad termestina (caballos, ovejas, lana, cuero, pez) está reflejada en un texto anterior al momento del sometimiento de la ciudad a Roma. En el 140-139 a.C., los romanos ofrecieron hacer la paz con Numantia y con Termes, siempre que cada ciudad aceptara entregar a los romanos 300 rehenes, 9.000 mantos (de lana), 3.000 odres de cuero, 800 caballos y todas las armas. ${ }^{74} \mathrm{Y}$ no puede olvidarse que los odres de cuero eran impermeabilizados con pez.

Sometida más tarde Termes a Roma a través de una deditio, el Estado romano reorganizó el territorio de la ciudad. Lo mismo que se venía haciendo en otras partes, las minas, las canteras, los pastos, las salinas..., y también las grandes extensiones de pinos, de donde se obtenía la pez, quedaban como dominios públicos del Estado. La explotación de esos grandes dominios corría a cargo de societates privadas que contrataban por periodos de cinco años, renovables por otros cinco. Como sucedió en otras muchas partes, un sector de las oligarquías locales que fue accediendo a la ciudadanía latina o romana se sumó pronto a los componentes de esas societates. En Termes, además de un importante grupo de ganaderos, pudo haber societates picariae de ítalo-romanos desde poco después de su sometimiento a Roma. Hay que resaltar que la pez era necesaria para impermeabilizar recipientes muy diversos (de cuero, de cerámica e incluso de esparto), así como para calafatear barcos e incluso como componente de armas incendiarias o para la iluminación nocturna. Se consumían, pues, cientos de toneladas de pez y no era inconveniente alguno el que muchas áreas pezgueras se situaran en el interior de la Península, como era el caso de Termes, ya que siempre se contó con las mejores vías de transporte, las vías fluviales, para llevar la pez a largas distancias. ${ }^{75}$ Tales rasgos económicos de Termes estuvieron en la base de una pronta romanización de la ciudad, lo que explica por qué adquirió un estatuto de municipio a comienzos del Imperio.

Dada la multiplicidad de funciones de Lug, cabe interpretar que, a veces, se asimiló en Hispania con Mercurius. Otros teónimos prerromanos podrían aludir a una divinidad de la misma naturaleza: así, el Arentius lusitano y el Vestius Aloenicus galaico. ${ }^{76}$ También sería rastreable el culto de Lug a partir de la iconografía, como en el relieve de la villa de Montemayor (Salamanca, donde el dios estaría representado por las tres cabezas unidas), en la cabeza bifronte cornuda de Jano de Candelario (Salamanca) y en la estatuilla de Mercurius de Castro Urdiales (Santander), que también representarían al dios. ${ }^{77}$

74 Diod. Sic., Bibl., 33, 16.

75 Mangas - Novillo 2013 e.p.

76 Olivares 2002, 203 y ss. Entre los primeros cabría considerar el Mercurius Aguaecus de S. Pedro do Sul (Viseu; HEp 4, 1994, 1101), el Mercurius Colualis de Salvatierra de Santiago (Cáceres; AE 1904, 157; HEp 2, 1990, 220) y el Mercurius Visuceu de Agoncillo (La Rioja; AE 1976, 327), a los que sumaríamos el Mercurius Esibraeus de Medelim (Idanha-a-Nova, Castelo Branco; AE 1967, 140).

77 Olivares 2002, 209-210. 


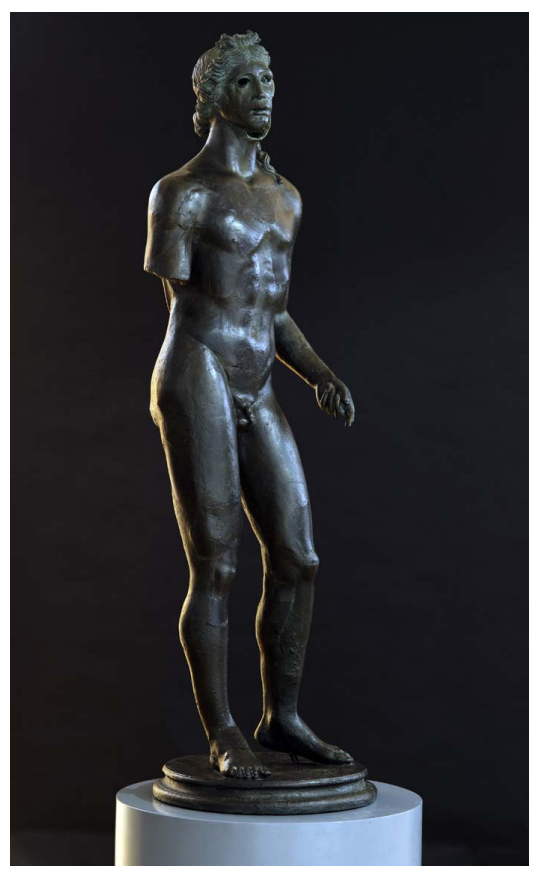

Fig. 6. Apollo de Termes, en bronce. Museo Arqueológico Nacional. (Foto: Museo Numantino, Soria).

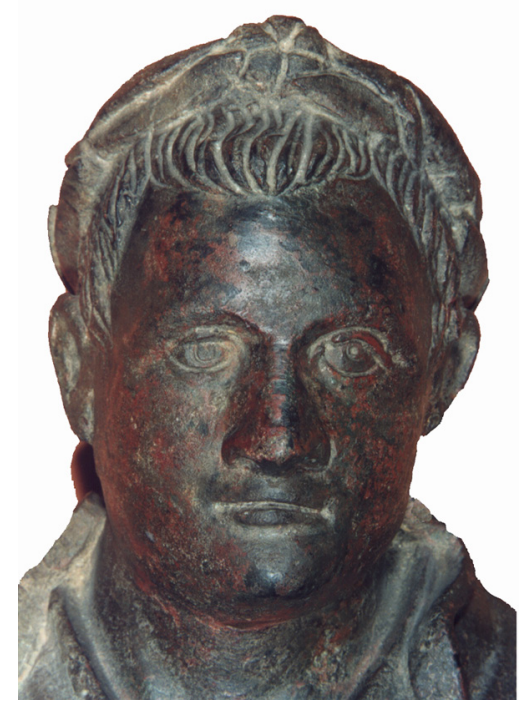

Fig. 7. Busto de sacerdote de Apollo, del santuario de Termes, en bronce. Museo Arqueológico Nacional. (Foto: C. Mayordomo - S. Martínez). 
El proceso de sincretismo que debió darse en Termes en relación con este tipo de divinidades multifuncionales prerromanas tiene paralelos en la misma región celtibérica, según nos consta por las fuentes epigráficas y por la iconografía. En la vecina ciudad arévaca de Vxama se conocen una dedicatoria a los Lugoues y otra a Mercurius Augustus, lo que puede señalar la interpretatio romana de la deidad solar. ${ }^{78}$ En la arévaca Confluentia (Duratón), heredera del oppidum celtibérico de Sepúlveda, se ha recuperado una cabecita de Mercurius, en terracota, perteneciente a una estatuilla de un lararium, y un torso de Apollo en mármol. ${ }^{79}$ En esta ciudad, Apollo y Mercurius podrían derivar del desdoblamiento funcional de una divinidad prerromana multifuncional. Se refuerza ese probable sincretismo cuando comprobamos el testimonio sobre las Matres en Confluentia, asociadas con frecuencia al culto de Lug. ${ }^{80}$

En Arcobriga (Monreal de Ariza), en un área celtibérica de difícil adscripción étnica, se conoce una dedicatoria a Mercurius ${ }^{81}$ Desde el análisis del vaso de Arcobriga, Marco propone que la figura pintada en este objeto podría representar a Lug o Arco. Arco sería una divinidad que podría tener unas características funcionales similares a las de Lug y el Mercurius céltico. ${ }^{82}$ Estos datos llevan a plantear la hipótesis de que, en Arcobriga, se habría producido una asimilación entre Arco, divinidad tutelar de la ciudad (sin duda, por el topónimo teofórico), y Mercurius. Arco también está testimoniado en el territorio termestino, en dos epígrafes procedentes de Saldaña de Ayllón (Segovia), ${ }^{83}$ por lo que Arco sería una divinidad regional que presentaría una naturaleza similar a Lug, siguiendo el esquema del Arentius lusitano y el Vestius Aloenicus galaico.

En el área berona es bien conocido el culto de Mercurius, en el territorio de $\mathrm{Va}$ reia (Varea, la Rioja). En Murillo del Río Leza el epíteto Compitalis que porta el dios incide en la función protectora de las vías y del comercio, como el Mercurius galorromano, ${ }^{84}$ del que nos habla César. ${ }^{85}$ En Agoncillo, ${ }^{86}$ una de las dos dedicatorias a Mercurius recuperadas en la zona contiene el epíteto Visuceu (documentado como Visucio en Gallia y Germania), ${ }^{87}$ que señala la probable derivación del culto desde una divinidad de la naturaleza de Lug. ${ }^{88}$ También en esta área se documenta una es-

78 CIL II 2818; ERPS, 38-40, $\mathrm{n}^{\circ} 22$.

79 Mangas - Martínez Caballero 2010, 341-342.

80 La presencia de estas deidades en Duratón podría tener alguna relación con la el culto acuático de Bonus Eventus (CIL II 3089; ERSg, 234-235, no 159), quizás de origen prelatino, en un lucus junto al río Duratón, en Puente Talcano, a los pies del oppidum de Sepúlveda (cf. Mangas - Martínez 2010; Martínez e.p. (b). La asociación de las Matres y las Nymphae, en conexión con un posible origen sincrético de cultos acuáticos romanos, se advierte también en Los Bañales.

81 HEp 15, 2006, 368; HEpOL 25022: Me/rcur/io / L(ucius) · Silius / Toloco. Con precedencia se había leído Mercurio Ocnioroco.

82 MARCO 2003.

83 ERSg 58 y 59. Sobre el santuario: Mangas -MartíneZ 2010.

84 CIL II 5810.

85 Caes., $B G 6.17$.

86 Agoncillo: AE 1976, 327 = ERRioja (Mercurius Visuceu). Luquín, Agoncillo: HEp 5, 1995, 620 = HEp 5, 1995, $621=$ HEp 9, 1999, 434 (Mercurius).

87 CIL XIII 5777, 3660, 4257, 6118, 6384, 4478, 5991, 6404 y 6347.

88 Olivares 2002, 211. 
pecial presencia del culto de las Matres. Podría repetirse en Vareia el esquema de la posible complementariedad de cultos prerromanos advertido en Confluentia.

Aunque puede tratarse ya de una difusión plenamente romana, no es imposible que algunas otras formas de devoción a Mercurio tengan un sustrato prerromano. Nos referimos a casos como los de las estatuillas de Mercurius de pequeño tamaño, relacionadas con cultos domésticos y lararios, halladas en Salas de los Infantes, en el territorio de la árevaca Nova Augusta; en Pinar Nuevo, junto a la vaccea Cauca (Coca, Segovia); y en Cubillas de Cerrato (Palencia), también en zona vaccea. Estas piezas abundan en el conocimiento de la especial veneración de la deidad romana en este ámbito céltico meseteño. Resulta razonable la concreción de un culto a Mercurius en la zona desde cultos prerromanos de la naturaleza de Lug. ${ }^{89}$ Precisamente en el contexto vacceo se considera también que las Duillae documentadas en Pallantia (Palencia) se relacionan con las Matres, incidiendo de nuevo en el argumento de la interrelación entre estos cultos en esta área céltica. ${ }^{90}$ En la parte superior del ara de las Duillae había tres imágenes femeninas -hoy desaparecidas- semejantes a las que se ven en las aras de las Matres de Colonia.

Contamos también con el controvertido topónimo $* *$ boruoturom $=$ Borvodurum, de la comunidad mencionada en una tésera de Vxama, que podría localizarse en el territorio extendido entre el Duero, Vxama y Termes. ${ }^{91}$ Se ha querido situar en Gormaz (Soria), en cuyas inmediaciones se sitúa el pequeño yacimiento celtibérico y romano de Fuentes Grandes, junto a los manantiales homónimos. Es significativo también que el epígrafe de Lameira esté dedicado por un uxamense. Del texto de la tésera de Vxama se deduce que la comunidad de Borvodurum quizás habría sido incluida en el territorio de aquella. Los datos nos podrían llevar a pensar que el voto en Lameira se podría explicar por la devoción de un uxamense por una divinidad bien conocida en su área de origen, Bormo/Borvo, una divinidad solar, acuática y salutífera habitualmente identificada con Apollo. No obstante, desde la propuesta de Jordán sobre una lectura dual del celtibérico occidental, se podría deducir que el topónimo sería Tarvodurum/Tarvoturum, derivable de Tarvos ${ }^{92}$, deidad gala también solar (Tarvos Trigaranus), conocida en el Pilar de los Nautae Parisiaci de Lutetia (París). ${ }^{93}$

Otro ejemplo de pervivencia de una divinidad céltica en la región celtibérica es el de Epona. Se trata de una deidad de funciones complejas muy ligada también a las Matres, por su vinculación con el ámbito ctónico y funerario. Aparece como gran madre y diosa de la fertilidad, las aguas, la prosperidad y la abundancia, con contenidos también salutíferos. ${ }^{94}$ Epona se documenta también en el área arévaco-pelendona, en Lara de los Infantes, Segontia y, gracias a un reciente hallazgo, en Confluentia. ${ }^{95}$

89 Salas de los Infantes y Cubillas de Cerrato: García y Bellido 1949, 69 y 87, nº 67 y 69; RodÁ 1990, 81. Pinar Nuevo: Blanco 1997, 386; Cabañero 2011, 110.

90 EE IX, 295 y 296; Blázquez 1962, 67-68. Ver Olivares 2002, 123-124.

91 García Merino - Untermann 1999.

92 Jordán CÓlera 2005, 1014 y ss.

93 GreEN 1989, 169 y s.; ID. 1992, 93 y ss.; ReINACH 1996.

94 Sobre el culto de Epona en Hispania: Elorza 1970; Olivares 2002, 251-254.

95 Lara de los Infantes: ABÁsolo 1974, 50, nº 40. Segontia: Olivares 2002, 120. La inscripción de Duratón ha sido recientemente hallada por el equipo de Aratikos S. L., bajo la dirección de Ángel L. Palomino Lázaro, 
Como observamos, el área de distribución de los testimonios de los cultos de Lug, las Matres (además de Epona) y de divinidades solares célticas, así como de Mercurius, Apollo y las Parcae en Hispania es coincidente en las ciudades y territorios del ámbito celtibérico noroccidental, en territorio arévaco, pelendón y berón: Apollo, Mercurius, Parcae y Arco en Termes; Apollo, Mercurius, Matres y Epona en Confluentia; Lugoves y Mercurius en Vxama; las Matres en Clunia; Mercurius, las Matres y Epona en Nova Augusta; Arco y Mercurius en Arcobriga; las Matres y Mercurius en Vareia; Epona y quizás Lugus/Lugoves en Segontia; y ¿Bormo/Tarvos en Tarvodurum/Borvodurum? Este sistema habría sido compartido, por influjo cultural, por comunidades vacceas orientales, según se desprende de la veneración de Mercurius en Cauca y de Mercurius y Duillae (¿Lugoves y Matres locales?) en Pallantia.

El que en Termes no contemos con un texto que informe sobre un epíteto de Apollo no excluye reconocer un proceso de sincretismo. Así lo muestra el hecho de que algunas inscripciones dedicadas al dios sin epíteto aparecen en santuarios donde se reconoce, por otras inscripciones o por el topónimo teofórico, el culto sincrético, como en los santuarios de Apollo Grannus en Hochscheid y Alchbachtal (junto a Augusta Treverorum), en Gallia Belgica, en Flavigny en Aquitania, en Aquae Grannius y Grossbottwar en Germania, o en Aquincum en Pannonia. ${ }^{96}$ Apollo sin epíteto también se documenta en santuarios de tradición céltica, ${ }^{97}$ dato que lleva a considerar la veneración de un dios procedente, de una interpretatio.

Este mecanismo sincrético podría también detectarse en lugares donde se documenta Apollo en compañía de fórmulas como Apollo et Genius o Numini Augusti, desde la invocación a unas fuerzas protectoras imperiales que podrían constituir en algún caso una sutil derivación de la función tutelar y protectora de los cultos prerromanos tópicos, enlazando con la identificación del Genius con la divinidad tutelar ancestral o poliádica. ${ }^{98}$ Siguiendo este sistema, este sincretismo se podría detectar en ámbitos rurales, donde las creencias prerromanas tendían a pervivir con mayor fuerza, a través de la evaluación de dedicatorias a Apollo Augustus o al Genius Apollini. ${ }^{99}$ En Flavigny, en Aquitania, queda patente en los votos a Augustus Apollo et Sirona. ${ }^{100}$

quien está procediendo a su análisis, y a quien agradecemos la noticia del hallazgo.

96 Apollo: AE 1941, 88; AE 1978, 516 (Hochscheid); GrenIER 1960, 857 y ss. (Alchbachtal, Trier). Deo Apollo et Sancta Sirona: AE 1941, 89 (Hochscheid). Dea Sirona: AE 1958, 153 (Flavigny, Côte-d'Or). Apollo: AE 1968, 323 (Aquae Granni, Aachen). Augusto Apollo et Divi Apollo et Sirona: AE 1994, 1305 (Grossbottwar). Apollo: CIL III 3631 (Aquincum, Budapest).

97 Son los casos de Gué de Sciaux (Antigny, Vienne; ILB-2, 139), Les Bons-Villers (Liberchies; $A E$ 2002, 1023), Tabernia (Tawern; $A E$ 1994, 1250-1254, 1257), Wallerfangen (AE 1991, 1249; AE 1995, 1104), Niedaltdorf $(A E 2005,1106)$ y Argentovaria (Oedenburg, Biesheim). Sobre estos santuarios: TRUNK 1991; FAUDUET 2010.

98 CIL XIII 1318 (Le Peu-Berland); AE 1962, 225 (Limonum, Poitiers); AE 1910, 121; CIL XIII 11241 (Alesia, Alise-Sainte-Reine, Côte d'Or); CIL V 741 y 748 (Aquileia), AE 1984, 641 (Vindinum, Le Mans, Sarthe).

99 CIL XIII 6390 (vicus Nediensis, Lobbach); CIL XII 2374 (Balme, Isére, Savoie); AE 1936, 112 (Grésysur-Isère, Savoie); $A E$ 1990, 718 (Gué de Sciaux); $A E$ 1978, 583 (Mertingen-Burghöfe).

$100 A E$ 1958, 153 (Flavigny, Côte d'Or). 
La extensión del culto de Apollo a partir de un proceso de sincretismo puede tener su reflejo en otros ámbitos de la Hispania céltica: ${ }^{101}$ el [Gen]ius Apollin[is] de Ponferrada ${ }^{102}$ podría tener un origen sincrético. En Lancia (Villasabariego, León) Apollo fue venerado por una cofradía religiosa (dumus), formada por veteranos que habían estado en el Bajo Danubio, donde conocieron ese modelo de asociación. ${ }^{103}$ ¿Existía ya en Lancia un culto de Apollo? Un caso distinto es el del Apollo Grannus de Asturica Augusta, que refleja la devoción de un procurator que venía del noroeste de Asia Menor y de la zona de Grant, ${ }^{104}$ lo que no indica que pudiera existir ya en Asturica Augusta un culto sincrético de Apollo, pues la deidad es bien conocida en la región. Recordamos la especial veneración de Apollo y Mercurius en la zona astur leonesa. ${ }^{105}$

La asociación de las Matres y Apollo en la exedra de Los Bañales, en conexión con el origen de las dedicatorias en unos votos realizados ex testamento por una evérgeta que habría acudido, con fines curativos, a un balneum o recinto termal, orienta sobre el posible origen prerromano de este Apollo salutífero, venerado junto a deidades célticas salutíferas (las Matres), así como junto a las Nymphae y Júpiter.

Otros testimonios de la Hispania céltica podrían proceder también de un proceso de sincretismo, ${ }^{106}$ pero al carecer de un epíteto prelatino, habría que evaluar cada caso en concreto con mayor profundidad. Baste el ejemplo del culto salutífero acuático a Apollo de Valencia de Alcántara, un lugar frecuentado desde la etapa prerromana y más tarde vinculado también con Salus ${ }^{107}$ (una diosa que es asimilada a Silbis, deidad acuática o ninfa de un santuario de aguas, o del río Queiles, conocida en acuñaciones de Turiasso -Tarazona, Zaragoza). ${ }^{108}$

En el territorium de Olisipo se situaba el santuario prerromano de Alto da Vigia (Praia das Maçãs, Colares), junto a Sintra, dedicado a deidades identificadas con el Sol y la Luna, ${ }^{109}$ y especialmente frecuentado por los gobernadores y procuradores lusitanos de época severiana. ${ }^{110} \mathrm{El}$ lugar se vincula a un culto solar de importante relevancia entre la población indígena, luego utilizado por el poder romano para la promoción del culto imperial, desde la vinculación del emperador y la aeternitas Imperii con el Sol Aeternus y la Luna, derivados de la epiclesis de sendas deidades prelatinas. Cabe reseñar que en Olisipo, aparte del testimonio del culto a Apollo, también se documenta el de Diana, paredros habitual de Apollo, y el de Mercurius. ${ }^{111}$ Diana es

\footnotetext{
101 Mangas 1992.

102 IRPLeón $45+$ MANGAS 1992, 180-181, nº 13.

103 MANGAS 1981-85; ID. 1996.

104 AE 1968, 86. Cf. MANGAS 1992, 181.

105 También se conocen en la zona el culto a Mercurius, en Ponferrada (CIL II 5706), León (CIL II 5678 y 5693), Carucedo (HEp 3, 1993, 245, Mercurius Augustus), Villar de los Barrios (ILER 276) y Toral de los Vados (HEp 3, 1993, 245).

106 Valencia de Alcántara: AE 1968, 211; CPILC 593. Conimbriga: AE 1924, 12. Olisipo: AE 1936, 107 ; 1953, 256. Telhado: HEp 10, 2000, 722. Beringel: $A E$ 1958, 48. Pax Iulia: IRCP $286=A E 1958,48=R A P$ 236. Arucci/Turobriga: CIL II $964=E R B C 161=I L S 5402$.

107 Olivares 1999.

108 Beltrán 2002, 50. Sobre la moneda: García-Bellido - BlázQuez 2001, 374.

109 CIL II 258-259.

110 CARDIM 2002; Marco 2009.

111 Diana: RAP 244 = AE 1950, 254. Mercurius: CIL II 180 y 181 (Augustus), HAE 407.
} 
asimilable a la Luna, en su equiparación a la Noctiluca latina ("Luz Nocturna") ${ }^{112}$ y la Selene y Hécate griegas, vinculadas a la Ártemis jonia. Esta versión de Ártemis ligada a luz lunar forma parte del sistema cultual solar, donde enfrente encontramos a Apollo Phosphóros, dios portador de luz, epíteto común del Apollo solar y también sincrético en algunos lugares europeos. En el santuario de Colares, la veneración prelatina solar, urania y lunar, relacionada con aspectos ctónicos (habitual en la concepción de la Luna en las religiones célticas hispanas), ${ }^{113}$ podría ser un apoyo para explicar el origen del culto de Apollo y Diana en la Olisipo romana.

\section{Apollo, las Parcae y las Matres, ¿en el templo del arx de Termes?}

El culto de un Apollo sincrético en Termes, conectado con un culto de las Parcae posiblemente derivado de la interpretatio de las Matres, se materializó en la ciudad en la construcción de un importante santuario urbano. Así lo declaran sus dimensiones y su ubicación topográfica preferente, junto al foro.

Es un esquema que remite a numerosos casos de la Keltiké, donde se documentan la transformación y monumentalización de antiguos santuarios indígenas, o la construcción de nuevos templos y santuarios urbanos, con formas clásicas o de tradición céltica, dedicados a un Apollo sincrético de importante proyección en la comunidad. ${ }^{114}$ Esta preeminencia del culto sincrético se explica en ciertos casos por el carácter plurifuncional del culto prerromano, es decir, por haber estado dedicado a una deidad que, con función tutelar y protectora, ocupaba una posición principal en las creencias, teología y representación pública de la ciudad. ${ }^{115}$

La transformación y monumentalización de este tipo de santuarios dedicados a un Apollo sincrético se advierte también en centros menores, donde se conocen numerosos templos rurales monumentalizados en época romana dedicados a este tipo de culto, en especial cuando se corresponde con el culto de carácter salutífero y termal de Apollo Bormo y Grannus. ${ }^{116}$ En algunos casos, especialmente en Gallia y Germania, la proyección del culto convierte a la deidad en epónima de vici, centros urbanos y civitates (Aquae Granni, Aquae Bormonis Lingonensis, Borbetomagus, etc.), surgidos desde la especial frecuentación de estos santuarios.

La lógica reflexión siguiente lleva a preguntarnos si la divinidad indígena transformada en Apollo en Termes fue la titular del culto del templo prerromano documenta-

112 Varr., De lin. lat. V.68; Hor., Carm. 4.6.37-40; Macr., Sat. 3.8.3.

113 A esta perspectiva aludiría Str. 3.4.16, al hablar del dios innominado que los celtíberos festejan las noches de luna llena.

114 En la Gallia Lugdunensis contamos con los templos de Lugdunum (Lyon, Rhône), Andesina (Grand, Vosges), Autessiodorum (Auxerre, l'Yonne), Condate (Rennes, Ille-et-Vilaine), Augustodunum (Autun, Saona-et-Lôire) y Augusta Rauricorum (August). En Aquitania, el templo de Apollo Moristasgus de Alesia (Alise-Sainte-Reine, Côte d'Or). En Germania, los templos de Vesontio (Besançon, Doubs) y Altiaia (Alzay). En Noricum, el templo de Teurnia (Spittal an der Drau). Y en Pannonia, el templo de Brigetio (Szöny).

115 Bendling 2001, 899-900.

116 Gallia: Fauduet 2010. Germania y Raetia: Trunk 1991; Spickermann 2001; Eingartner et alii 1993. Britannia: RIB 99b. 
do en el arx, dado que la posición topográfica de este templo en la parte más alta de la ciudad apunta al carácter poliádico de su culto. La hipótesis parte de considerar que la divinidad celtibérica poliádica habría ofrecido un componente de arraigo ideológico fundamental para cohesionar la comunidad cívica termestina tras la conquista. La interpretatio de la deidad céltica y la consiguiente transformación del sistema de creencias y rituales, formulado en la oficialidad de un culto de Apollo (luego estrechamente ligado, desde Augusto, a la ideología imperial), habría contribuido a la integración de la comunidad local en las nuevas pautas de organización romanas, derivando en la paulatina transformación ideológica de la sociedad.

Como no contamos con ningún testimonio literario, epigráfico o arqueológico que garantice cuáles eran la o las divinidades que recibieron culto en el arx de Termes, caben muchas hipótesis y muchos paralelismos. Entre todos, resulta razonable el pensar que, en el templo poliádico prerromano del arx, recibió culto una divinidad poliádica de carácter plurifuncional y solar -en la línea de los Lugoves- de la que se hizo heredera el Apollo reconocido en época imperial, resultado de un proceso sincrético.

Ese conjunto de hechos abre la posibilidad de que el sacellum de las Parcae junto al templo de Apollo de Termes recoja también un culto prerromano a la triada de divinidades femeninas célticas (¿Matres?) que pudieron recibir antes culto junto a un templo consagrado a una deidad plurifuncional (tipo Lugoves) en el ámbito del arx de la acrópolis. Tras el traslado del culto al primer foro de la ciudad bajo la forma de un culto a Apollo, se procedió también a la creación del sacellum de las Parcae, que podían derivar de una probable interpretatio de las Matres. Los datos arqueológicos orientan a que ese traslado tuvo lugar en época julio-claudia. Se habría repetido un esquema semejante al de otros lugares: así, en Glanum, se rindió culto a Apollo y las Matres Glanicae en posiciones muy cercanas.

Se abre igualmente la vía para esperar que los pozos rituales del ámbito del arx puedan estar conectados con la llamada cueva, lo que, de confirmarse, nos situaría ante alguna fatidica puella, a semejanza de lo que tenemos constatado sobre Clunia. Incluso si la inscripción recuperada por Schulten fuera, efectivamente, una dedicatoria a Mercurius, podríamos pensar en la bilateralidad funcional generada por sincretismo en época romana del culto del arx, que habría derivado en la promoción en época romana del culto de Apollo y Mercurius romanos.

Desde la perspectiva urbanística, siempre nos ha llamado la atención que el templo de Apollo de Termes se erigiera en un momento avanzado del s. I d.C. junto al foro, en época neroniana (54-68 d.C.), pues, en ese espacio público, hemos identificado fases constructivas ya desde el segundo cuarto del s. I a.C. Con los argumentos que hemos manejado, ese dato se puede contextualizar con el hecho de que, bien establecido el culto imperial en el templo foral, en época de Augusto - Tiberio, en época julioclaudia avanzada se procedió a la reubicación del todavía importante culto indígena del santuario del arx, en relación con la nueva promoción imperial del culto apolíneo por Nerón: a partir del 59 d.C., tras la muerte de Agripina, se atiende en la ideología oficial a una nueva Edad de Oro (aurea aetas) regida por Nerón, considerado el nuevo Apollo y el nuevo Sol/Helio. 
Pueden quedar dudas sobre si el abandono del santuario del arx fue puntual mediante su traslado al foro o bien si hubo un tiempo de duplicación cultual, lo que resulta más extraño.

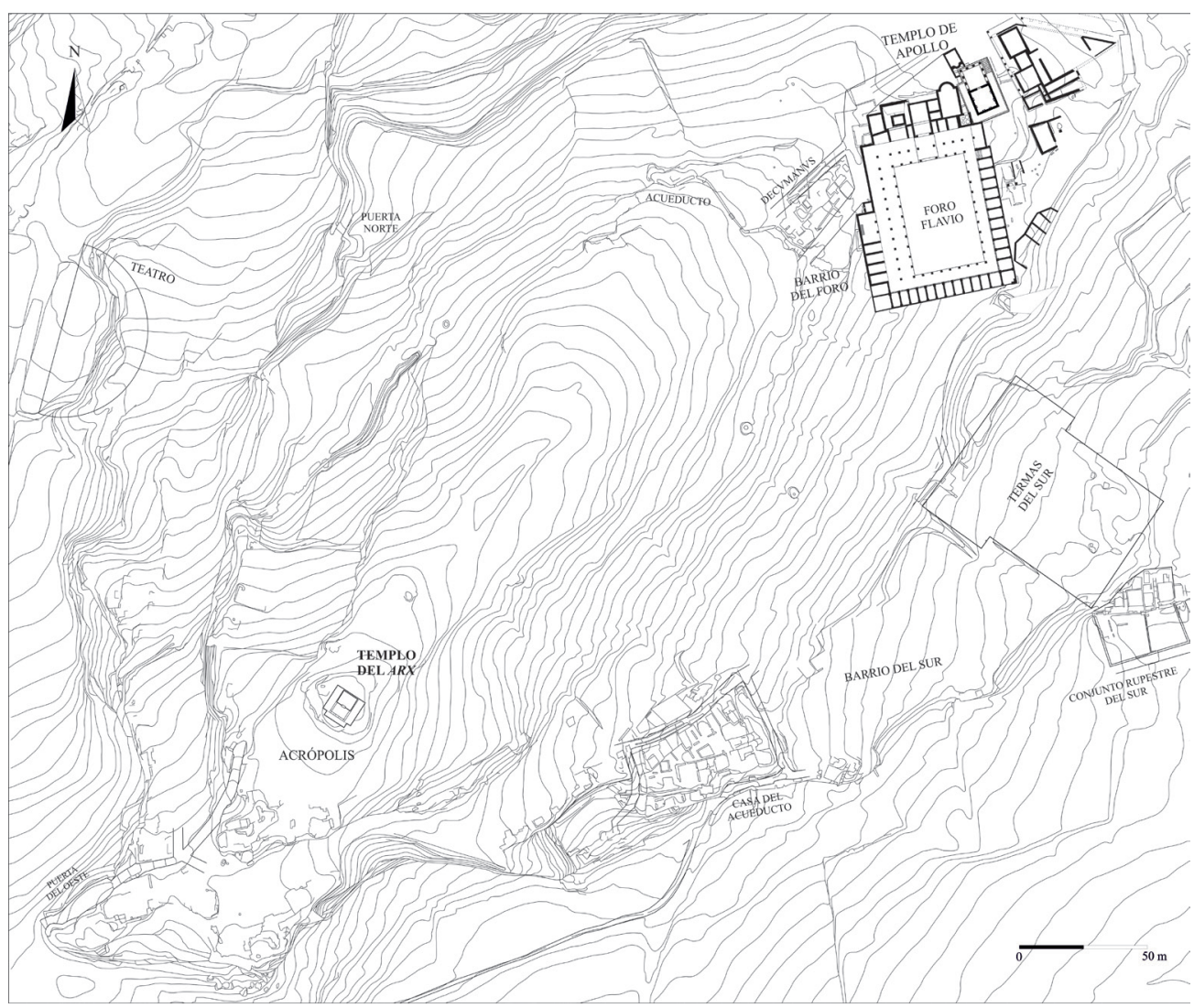

Fig. 8. Localización del santuario de Apollo y del santuario del Arx en Termes.

En cuanto al nombre de la deidad poliádica prerromana de Termes, de la que se hizo heredera el Apollo imperial, no hay documento que testimonie que Termes fuese el nombre de la deidad heroica y epónima de la ciudad celtíbera, como dijeron Almagro-Gorbea y Lorrio: “(...) la hipótesis más verosímil es que el titular debía de ser Termes, el Héros Ktístes de la ciudad (...)”. El carácter del topónimo Termes/Tarmes no implica la deducción automática de que la ciudad contara con un héroe fundador que portara ese nombre, versión local del Teutates tutelar. Siguiendo esa lógica, también podría suponerse que Termes/Tarmes podría haber sido el nombre de una divinidad epicórica de carácter solar y plurifuncional, no heroica, transposición o proyección local de los Lugoves. Incluso, dado que Arco es deidad regional, y posiblemente de carácter solar en Arcobriga, no sería excluible que, por estar documentada en el 
territorio termestino (espacio adscrito en época prerromana al oppidum de Ayllón), Arco pudiera corresponderse con la deidad de la que derivó el Apollo de Termes.

\section{Bibliografía}

Abásolo, J. A.

(1973): "El árula de Hontangas, la inscripción de Cuevas de Amaya y la estela de Fresneda de la Sierra (Burgos)", BSEAA XXXIX, 443-449.

(1974): Epigrafía romana de la región de Lara de los Infantes, Burgos.

Abásolo, J. A. - Alcalde, G. (1996): “Obbellegino en Cantabria”, [en] III Congreso de Historia de Palencia, Palencia, 303-314.

Alberro, M. (2010): “El pancéltico dios Lug y su presencia en España”, Polis 22, 7-30.

Alfayé, S. (2009): Santuarios y rituales en la Hispania céltica (=BAR International Series 1963), Oxford.

Almagro-Gorbea, M. (1994): "Saunas iniciáticas, termas celtibéricas y culto imperial”, [en] Mélanges Raymond Chevallier (=Caesarodunum XXVIII), Paris, 139-153.

Almagro-gorbea, M. - Abascal, J. M. (2008): “Termes y Segobriga y los orígenes del culto imperial en Hispania", [en] E. La Rocca et alii (eds.), Le due patrie acquisite. Studi di archeologia dedicati a Walter Trillmich (=Bullettino della Commissione Archeologica Comunale di Roma. Supplementi 18), Roma, 15-25.

Almagro-Gorbea, M. - Berrocal, L. M. (1997): "Entre iberos y celtas: sobre santuarios comunales urbanos y rituales gentilicios en Hispania", Quaderns de Prehistòria i Arqueologia de Castelló 18, 567-588.

Almagro-Gorbea, M. - Lorrio, A. (2012): Teutates. El Héroe Fundador (=Bibliotheca Archaeologica Hispana 36), Madrid.

Andreu, J. (2011): La ciudad romana de Los Bañales. Uncastillo - Zaragoza, Zaragoza.

Ares VÁzquez, J. L. (1972): “Exvotos de Lucoubu y Lugubo en Lugo”, BRAH 169, 185-195.

Argente, J. L. - DíAz, A.

(1990): Tiermes. Guía del Yacimiento arqueológico y Museo, Soria.

(1996): Tiermes. Guía del yacimiento y Museo, Valladolid.

Argente, J. L. et aliI (1988): Tiermes. Guía del yacimiento arqueológico, Madrid.

Arias, F. P. - Le Roux, P. - Tranoy, A. (1979): Inscriptions romaines de la province de Lugo, Paris.

Baratta, G. (2001): Il culto di Mercurio nella Penisola Iberica, Barcelona.

BAYET, J. (1969): Histoire politique et psychologique de la religion romaine, Paris.

Bedon, R. (2001): Atlas des villes, bourges, villages de France au passé romain, Paris.

BELTRÁN-LLORIS, F.

(1980): Epigrafia latina de Saguntum y su territorio, Valencia (=ELST).

(2002): "Les dieux des celtibères orientaux et les inscriptions: quelques remarques critiques", [en] AA. VV., Dieux des celtes. Études luxembourgoises d'Histoire \& de Science des religions 1, Luxembourg, vol. 1, 39-66. 
Beltrán-LLoris, F. - Jordán, C. - Marco, F. (2005): "Novedades epigráficas en Peñalba de Villastar (Teruel)", [en] Actas del IX Coloquio Internacional sobre Lenguas y Culturas Paleohispánicas (=Paleohispanica 5), Zaragoza, 911-956.

Blanco, F. (1997): “Aproximación a la Cauca del Bajo Imperio”, [en] Actas del Congreso Internacional la Hispania de Teodosio, Segovia, vol. 2, 377-393.

BlÁzquez, J. Ma (1962): Religiones primitivas de Hispania, Roma.

Blech, M. (1981): "Esculturas de Tajo Montero (Estepa): una interpretación iconográfica”, [en] AA. VV., La religión romana en Hispania, Madrid, 105-106.

Brelich, A. (1937): Aspetti della morte sulle iscrizioni sepolcrali dell'Impero, Roma.

CABAÑero, V. (2011): "SPQC. Senatu Populoque Caucensium”, [en] Historia de Coca. XXXII Curso de Historia de Segovia, Segovia, 101-130.

CAlvo, I. (1913): “Termes, ciudad celtíbero-arévaca”, RABM XXIX, 374-387.

CArdim, J. (2002): “Soli Aeterno Lunae. O Santuario”, [en] Religiões da Lusitânia. Loquuntur Saxa, Lisboa, 235-238.

Coarelli, F. (1997): Il Campo Marzio. Dalle origini alla fine della Repubblica, Roma.

Corell Vicent, J. (1994): “La Muntanyeta de Santa Bárbara (La Vilavella, Castellón). ¿Un santuario de Apolo?”, Anuari de Filologia. Secció D, Studia Graeca et latina 5, 155-188.

Corell Vicent, J. - Gómez Font, X. (COL.), (2005): Inscripcions romanes del País Valencià. II. 1. L'Alt Palància, Edeba, Lesera i els seus territoris. 2. Els mil.liaris del País Valencia, Valencià.

Correa, J. A. (1981): "Nota a la inscripción tartesia G. M. II", AEspA 54, 203-209.

DeonnA, W. (1941): “L'art national de la Suisse romaine. II. Le taureau à trois cornes de Martigny”, Genava XIX, 133-165.

De Angeli, S. (1992), “Moirai”, LIMC VI, 636-648.

De VRIeS, J. (1963): La religion des celtes, Paris.

DuMÉzIL, G. (1966): La religion romaine archä̈que, Paris.

Eingartner, J. - Eschbaumer, P. - Weber, G. (1993): Der römische Tempelbezirk in Faimingen-Phoebiana (=Limesforschungen 24), Mainz.

Elorza, J. C. (1970): "Un posible centro de culto a Epona en la provincia de Álava", Estudios de Arqueología Alavesa 4, 275-281.

Euskirchen, M. (1997): “Belenus, Belinus. Keltischer Gott”, Der Neue Pauly, II, StuttgartWeimar, 546-547.

Even, A. (1956): "Notes sur le Mercure celtique III. Le dieu celtique Lugus", Ogam 8, 81-110.

FAUduEt, I. (2010): Les temples de tradition céltique (nouvelle édition revue et augmentée), Paris.

Figueroa y Torres, A. De, Conde de Romanones (1910): Las Ruinas de Termes. Apuntes arqueológicos descriptivos, Madrid.

Gagé, J. (1955): Apollon Romain. Essai sur le culte d'Apollon et le développement du 'ritus graecus'à Rome, des origines à Auguste, Paris

GAlsterer, H. (1971): Untersuchungen zum römischen Städtwesen auf der Iberischen Halbinsel, Berlin. 
García Arias, J. L. (1976): "Vestigios toponímicos del culto a Beleno en Asturias", Boletín del Instituto de Estudios Asturianos 88-89, 793-799.

García-Bellido, Ma P. - Blázquez, C. (2001): Diccionario de cecas y pueblos ibéricos, Madrid, 2 vols.

García Merino, C. - Untermann, J. (1999): "Revisión de la lectura de la tessera Uxamensis y valoración de las téseras en el contexto de la configuración del poblamiento celtibérico en el s. I a. C.", BSEAA LXV, 138-152.

García Quintela, M. V. - Santos, M. (2008): Santuarios de la Galicia céltica. Arqueología del paisaje y religiones comparadas en la Edad del Hierro, Madrid.

García y Bellido, A. (1949): Esculturas romanas de España y Portugal, Madrid.

Goceva, Z. (1977): "Epitheta des Apollo in Thrakien”, Thracia 4, 207-223.

Gómez-Pantoja, J. L. (1999): “Las Madres de Clunia”, [en] F. Villar - F. Beltrán (eds.), Pueblos, lenguas y escrituras en la Hispania prerromana, Salamanca, 421-432.

Gómez SANTACRuZ, J. (1994): "La municipalización de Termes y su avance romanizador en época altoimperial", Hispania Antiqua 18, 159-170.

GonzÁlez Fernández, E. - Rodríguez Colmenero, A. (2002): "Dos hallazgos singulares en las recientes excavaciones de Lugo: un edículo sacro y un alfabeto latino de época romana", Larouco 3, 243-251.

González Román, C. - Mangas, J. (1991): Corpus de inscripciones latinas de Andalucía. Jaén, I-II, Sevilla (=CILA 6 y 7 ).

Green, M.

(1986): The Son-Gods of Ancient Europe, London.

(1992): Dictionary of Celtic Myth and Legend, London.

Grimal, P. (1965): Dictionnaire de la mythologie grécque et romaine, Paris.

Hatт, J. J. (1985): “Apollon guérisseur en Gaule: ses origines, son caractère, les divinités qui lui sont associées", [en] A. Pelletier (ed.), La médicine en Gaule, Paris, 185-218.

JoRdÁn Cólera, C.

(2005): “Sistema dual en celtibérico?”, [en] Acta Paleohispanica IX. Actas del IX Coloquio Internacional sobre Lenguas y Culturas Paleohispánicas (=Palaeohispanica 5), Zaragoza, 1013-1030.

(2005a): "[K.3.3]: crónica de un teicidio anunciado", Estudios de Lenguas y Epigrafía Antiguas 7, 37-72.

JordÁn Lorenzo, C. (2012): "Una donación ex testamento procedente del foro de Los Bañales (Uncastillo, Zaragoza)”, Espacio, Tiempo y Forma. Serie II, Historia Antigua 25, 75-92.

LAmbrechts, P. (1942): Contributions á l'étude des divinités céltiques, Brugge.

Le Roux, P. - Tranoy, A. (1973): "Notes d'épigraphie romaine de Galice", Cuadernos de Estudios Gallegos 28, 221-234.

Loth, J. (1914): “Le dieu Lug, la Terre Mere et les Lugoves”, Revue Archéologique 2, 205230.

Mac Cana, P. (1983): Celtic Mythology, Feltham.

MANGAS, J.

(1981-1985): "Dumus, cofradía religiosa de Apolo", Hispania Antiqua 11-12, 119-125. 
(1992): "El culto a Apolo en Hispania. Testimonios epigráficos", [en] Mélanges P. Lévêque, Paris, 171-192.

(1996): "Cultos minorasiáticos en el Noroeste de la Hispania romana", Complutum Extra 6/1, 483-490.

Mangas, J. - Martínez Caballero, S.

(2004): "Nuevas inscripciones romanas de Termes (Tiermes, Soria)", Veleia 21, 289-300.

(2010): "La religión de la población del territorio segoviano en época romana", [en] S. Martínez et alii (coords.), Segovia romana II. Gentes y territorios, Segovia, 335-358.

Mangas, J. - Novillo, M. A. (e.p.): “Ars picaria: extracción y usos de la pix en el mundo romano", [en] XVIII Congreso Internacional de Arqueología Clásica. Centro y periferia en el mundo clásico. Mérida, 13-17 de Mayo, 2013.

Mangas, J. - Novillo, M. A. (EDs.), (e.p.): Santuarios suburbanos y del territorio de las ciudades romanas, Madrid.

MARCO, F.

(1986): "El dios céltico Lug y el santuario de Peñalba de Villastar", [en] Estudios en Homenaje al Dr. Antonio Beltrán Martínez, Zaragoza, 731-759.

(1993): "La religiosidad en la Céltica hispana", [en] M. Almagro Gorbea - G. Ruiz Zapatero (eds.), Los Celtas: Hispania y Europa, Madrid, 477-512.

(2003): "Signa Deorum: comparación y contexto histórico en Hispania y Galia", [en] T. Tortosa - J. A. Santos (eds.), Arqueología e iconografia: indagar en las imágenes, Roma, 121-136.

(2006): "The cult of the Lugoves in Hispania", Acta Archaeologica Academiae Scientiarum Hungaricae 57, 209-218.

(2009): "Las inscripciones religiosas hispanas del ámbito rural como expresión del hábito epigráfico", [en] Espacios, usos y formas de la epigrafía hispana en épocas antigua y tardoantigua. Homenaje al Dr. Armin U. Stylow (=Anejos de AEspA XLVIII), Mérida, 197210.

Martínez Caballero, S.

(2007): "Monumentos honoríficos y escultura mitológica en bronce de la ciudad romana de Termes", [en] C. Fernández Ibáñez (ed.), Metalistería de la Hispania Romana (=Sautuola XIII), Santander, 363-376.

(2008): "Los territorios de los municipios del Sur del Conventus Cluniensis (Hispania Citerior) en el Alto Imperio: Termes, Duratón y Segovia", [en] J. Mangas - M. A. Novillo (eds.), El territorio de las ciudades romanas, Madrid, 187-247.

(2010): "El Foro romano de Termes (Hispania Citerior). Síntesis histórica, arqueológica y topográfica (s. I a. C.-s. IV d. C.)", AEspA 83, 221-266.

(2011): "El Foro romano de Termes (Hispania Citerior). Proceso de municipalización y difusión local de modelos arquitectónicos", [en] Actas del XI Coloquio Internacional de Arte Romano Provincial "Roma y las provincias: modelo y difusión" (Mérida, 18-21 de mayo, 2009), Mérida, 925-940.

(e.p.): "El Foro Flavio de Termes (Hispania Citerior). El modelo arquitectónico", [en] XVIII Congreso Internacional de Arqueología Clásica, Mérida.

(e.p., a): “Bonus Eventus en Puente Talcano (Sepúlveda, Segovia). Un santuario rural en el territorio del municipium de Duratón (Hispania Citerior)", [en] J. Mangas - M. A. Novillo (eds.), Santuarios suburbanos y del territorio de las ciudades romanas, Madrid.

Martínez Caballero, S. - Mangas J. (e.p.): Termes celtibérica. Origen, evolución y conquista romana. 
Martínez Caballero, S. - Santos, J. (2005): "Pervivencias indígenas en la Tiermes romana. Elementos para su evaluación", [en] Actas del IX Coloquio Internacional sobre Lenguas y Culturas Paleohispánicas (=Palaeohispanica 5), Zaragoza, 685-706.

Mayer, M. - AbÁsolo, J. A. (2001): "Estelas rupestres en Hispania. La necrópolis de Termes”, [en] Saxa Scripta. Actas do III Simposio ibero-italico de epigrafia rupestre, Viseu, 161179.

Moneo, T. (2003): Religio iberica. Santuarios, ritos y divinidades (siglos VII-I a.C.), (=Bibliotheca Archaeologica Hispana 20), Madrid.

Olivares, J. C. (2002): Los dioses de la Hispania Céltica (=Bibliotheca Archaeologica Hispana 15), Madrid.

Olmsted, G. S. (1994): The Gods of the Celts and the indoeuropeans, Budapest.

Perfigli, M. (2004): Indigitamenta. Divinità Funzionali e Funzionalità divina nella Religione Romana, Pisa.

Reinach, S. (1996): “Tarvos Trigaranos”, [en] Cultes, Mythes et religions, Paris, 240-248.

RodÁ, I. (1990): "Bronces romanos de la Hispania Citerior", [en] Los bronces romanos en España, Madrid, 71-90.

RÜGER, C. B. (1987): “Beobachtungen zu den epigraphischen Belegen der Muttergottheiten in den lateinischen Provinzen des Imperium Romanum", [en] H. Henss - G. Neumann (eds.), Matronen und verwandte Gottheiten, Köln, 1-30.

Ruiz-Nicoli, B. (2009): "Retrato de hombre romano", [en] Rostros de Roma. Retratos romanos del Museo Arqueológico Nacional, Segovia, 108-109.

SAgredo, L. - Hernández, L. (1996): "Los testimonios epigráficos de Lug en Hispania”, MHA XVII, 179-201.

Salinas, M. (1986): "El dios céltico Lug y el Santuario de Peñalba de Villastar", [en] Estudios en Homenaje al Dr. A. Beltrán Martínez, Zaragoza, 731-759.

SAn vicente, J. I. (2008): "El jinete desnudo y la silla de montar de la estela de Iruña (Álava)", Hispania Antiqua 32, 57-92.

Schulten, A. (1913): "Monumentos e Historia de Termancia", BRAH LXIII, 461-477 y 571582 (=A. Schulten, 1911).

Sentenach, N. (1911): “Termes”, RABM XXIV, 285-294.

Sergent, B. (1995): Lug et Apollon, Bruxelles.

Solana, J. Ma . - Hernández, L. (2000): Religión y sociedad de época romana en la Meseta Septentrional, Valladolid.

Solana, J. Ma . - SAgredo, L. - Hernández, L. (1995): "Epigrafía y numismática de Atapuerca. Burgos”, Hispania Antiqua 19, 191-203.

SOPEÑA, G.

(1987): Dioses, ética y ritos. Aproximación para una comprensión de la religiosidad entre los pueblos celtibéricos, Zaragoza.

(2009): "Mors: una imagen esquiva", [en] F. Marco - F. Pina - J. Remesal (eds.), Formae mortis: el tránsito de la vida a la muerte en las sociedades antiguas, Barcelona, 253-282.

TARACENA, B.

(1941): Carta Arqueológica de España. Soria, Madrid. 
(1954): "Los pueblos celtibéricos”, [en] R. Menéndez Pidal (dir.), Historia de España, Madrid, Tomo I, vol. 3, 238-242.

Tels de Jong, L . L. (1959): Sur quelques divinités romaines de la naissance et de la prophétié, Delft.

Thévenot, E. (1968): Divinités et sanctuaires de la Gaule, Paris.

Tovar, A. (1982): “The God Lugus in Spain”, Bulletin of the Board of Celtic Studies XXIX, 591-599.

TRunK, M. (1991): Römische Tempel in den Rhein- und westlichen Donauprovinzen, Augst.

VAllejo, J. Ma (2005): Antroponimia indígena de la Lusitania romana (=Anejos de Veleia, Serie minor 23), Vitoria.

VAn der Horst, P. C. (1942): "Fatum, Tria Fata, Parca, Tres Parcae", Mnemosyne 11, $217-$ 227.

Vendryes, J. (1948): La religion des Celtes, Paris.

Weinstock, S. (1952): "Parca Maurtia und Neuna Fata”, [en] Festchrift Andreas Rumpf, Krefeld, 151-160.

Wiegels, R. (1985): Die Tribusinschriften des römischen Hispanien (=Madrider Forschungen 13), Berlin.

Wojciechowski, P. (1996): “Belenus, die Schutzgottheit von Aquileia”, Eos 84, 93-101.

ZACCARIA, C. (2010): “Belenus”, [en] P. C. Ramsl et alii (eds.), Lexikon zur keltischen Archäologie, Wien. 